\title{
Chapter 3 \\ The Drivers of Global Value Chain \\ Participation: Cross-Country Analyses
}

Building on the work of Jones and Kierzkowski (1990), economists have been writing models that describe how firms are increasingly fragmenting production processes into various stages or tasks and moving them to more advantageous locations (e.g., Deardorff, 2001a, 2001b; Findlay \& Jones, 2001; Grossman \& RossiHansberg, 2008; Jones \& Kierzkowski, 2000, 2001). Most of the models in this literature draw on findings from an earlier literature on FDI, namely that firms will fragment production or tasks across different countries to arbitrage international differences in factor prices (Helpman, 1984; Helpman \& Krugman, 1985). ${ }^{1}$ The rationale behind most models of fragmentation can be stated in simple terms: in traditional production processes, inputs are organized and combined to generate final outputs in the same location. Where there are many inputs, coordination is normally necessary and proximity helps to lower the costs of coordination and transportation. But if firms could separate the production process into different production blocks and relocate them in places with lower factor prices, the total costs of production could be further reduced. Therefore firms will unbundle their production processes, as long as the resulting reduction in production costs would more than compensate for the additional costs of coordinating remotely located production blocks and moving these production blocks around.

\footnotetext{
${ }^{1}$ This class of models, called the vertical model of FDI, was developed in parallel with the horizontal model of FDI. In the latter model, the motive behind the multinational corporation (MNC) is to save on trade costs associated with exporting by setting up foreign subsidiaries producing similar goods to those produced at home (Horstmann \& Markusen, 1987; Markusen, 1984). Later on, the knowledge-capital model was developed, which allowed for simultaneous horizontal and vertical motives for FDI (Markusen, 1997). The new models of fragmentation are generally not exclusively limited to the study of multinationals. The main predictions of these new models tend to apply to companies that fragment production internationally, regardless of whether this is done within the boundaries of the firm or through independent suppliers. Another strand of the literature examines the more specific issue of whether the fragmentation of production occurs within the boundaries of the firm or through an independent supplier (Antràs, 2003; Antràs \& Helpman, 2004, 2008). This is called the internalization decision.
} 
This model highlights the main forces behind the international unbundling of production: on the one hand, there are comparative advantage considerations, such as differences in factor prices that make offshoring attractive. But on the other hand, additional costs related to offshoring need to be factored in. Therefore, the unbundling of production will take place if the lower marginal costs of production more than offset these extra costs related to offshoring. ${ }^{2}$

This reasoning helps explain why some countries, such as China, are attractive destinations for offshoring: when the marginal costs of production are very low they almost always compensate for the extra costs related to offshoring. By the same token, however, countries with mid- to high-factor prices have a greater need to avoid the extra costs of offshoring to become attractive destinations.

Different offshoring costs have been highlighted in the literature. For instance, high transportation costs are likely to discourage the movement of intermediate inputs between countries. Similarly, inadequate telecommunication services would make it harder for a firm to coordinate with production units located abroad (Jones $\&$ Kierzkowski, 1990). In addition, tariff barriers and costly custom clearances will drive up the prices of imported inputs, especially if they cross international borders many times. Finally, high costs of dealing with legal procedures in another country in the event of a breach of contract would likely limit offshoring decisions in that country (Jones \& Kierzkowski, 2001). As shown in Chap. 1, many of these obstacles have been declining in recent years.

In this chapter we analyze the impact of reducing some of these costs on offshoring decisions. The aim is to identify potential avenues by which countries in Latin America and the Caribbean could improve their participation in production networks. To add nuance to the analysis, the discussion is divided into four sections. The first section looks at the role of transportation and logistics services, including communication and information technology. The second section analyzes the impact of trade agreements and trade policy in general. In the third section we examine the factors behind the decision to fragment production through vertical FDI versus foreign outsourcing, which naturally leads to the subject of contract enforcement. Finally, section "Service Offshoring: Grasping the Intangibles" studies the determinants of service offshoring. As mentioned in the introduction, the list of potential drivers behind the formation of global supply chains can be quite extensive. In this chapter we look into areas that seem most relevant in terms of insights contained in the literature and opportunities for public policy solutions. ${ }^{3}$

\footnotetext{
${ }^{2}$ There is a parallel and influential literature on GVCs that depend less on general or partial equilibrium economic models and more on the typologies of linkages in GVCs and the characteristics of the units that participate in them (see, for instance, Gereffi, 1999; Gereffi, Humphrey, \& Sturgeon, 2005; Humphrey \& Schmitz, 2000). In this literature the analysis is mostly focused on the governance dimension of the value chain. In other words, central to this literature is the study of power relations across the units of the value chains and how these relations affect issues such as transfer of knowledge or learning. We will address some of these aspects in Chap. 4 of this report. ${ }^{3}$ In the next chapter we take a much closer look at the issue of the supplier's capabilities.
} 
Each section presents recent relevant empirical studies that address specific issues behind the drivers of offshoring. While each model is tailored to the particular determinant being addressed, they are all estimated in ways that control for other elements that may impact offshoring decisions.

\section{Synchronizing Trade: The Role of Transportation, Communication, and Logistics Infrastructure}

Firms that fragment production internationally incur risks. One is the possibility of delays in the arrival of components, which can result in shutting down entire production lines until the necessary inputs have arrived. Firms can address this uncertainty by maintaining large inventories of components. However, modern supply chain practices are increasingly moving towards so-called "lean production" strategies, which involve keeping low inventories to cut costs. Accordingly, firms fragmenting production internationally are likely to look for locations with adequate transport and logistics infrastructure to reduce disruptions in the supply chain, inventory-holding costs, depreciation costs, and handling costs. In this section we present empirical evidence on the link between logistics infrastructure and the international location of fragmented production. The objective is to measure the extent to which deficiencies in Latin America's logistics infrastructure are standing in the way of the region's greater participation in global supply chains.

We will begin by comparing Latin America with other regions in terms of logistics infrastructure indicators that measure three dimensions relevant for the location of fragmented production. The first two dimensions are the quality of the port and airport infrastructures; improvements in these facilities are associated with declines in transport costs, waiting times, and handling costs (Clark, Dollar, \& Micco, 2004; Limão \& Venables, 2002; Micco \& Serebrisky, 2006). Accordingly, countries with adequate port and airport infrastructures should be attractive locations for companies seeking to locate part of their production processes abroad while minimizing transportation costs and potential disruptions in the supply chain.

The third infrastructure dimension that we examine is the logistics required to coordinate production across space. As mentioned in Chap. 1, information and communication technology (ICT) infrastructure is crucial for providing firms the ability to move information over long distances quickly, cheaply, and reliably, and in this way lower the costs of coordinating production blocks across borders. The development of readily available and good quality ICT is needed to provide instant access to information for the numerous stakeholders in a global value chain, e-commerce for consumers, and logistics management. Therefore, countries need adequate ICT infrastructures to be attractive destinations for firms fragmenting production internationally.

Detailed data on port and airport efficiency are hard to find. In this chapter we use a combination of hard data and survey indicators for our estimations. First, we obtain hard micro data on port and airport characteristics to construct hard measures 
of port and airport availability at the country level. Following Clark et al. (2004), we use this data to construct a measure of seaport infrastructure that captures the country's ports that have adequate leverage capacity. ${ }^{4}$ Similarly, following Micco and Serebrisky (2006), we construct a measure of the availability of airports with runways capable of serving the air cargo industry. ${ }^{5}$ With respect to communications, we combine a series of hard indicators utilizing the core measures on ICT infrastructure suggested by The Partnership on Measuring ICT for Development. ${ }^{6,7}$ As mentioned above, we combine these hard data indicators with survey data from the Global Competitiveness Index, 2011, of the World Economic Forum. Specifically, we employ the "quality of port infrastructure," the "quality of air transport infrastructure," and the "quality of ICT infrastructure" indexes. We then normalize each of the hard data and survey indicators to take values between 1 and 100 .

Figure 3.1 compares the average of each of these indexes for the Latin American region, the EU, and Asia. The results speak for themselves. LAC, on average, clearly has less adequate logistics infrastructure (port, airport, and ICT infrastructure) than the other two regions, regardless of which measure we use. ${ }^{8}$ The relevant question then becomes the extent to which these shortcomings in logistics infrastructure reduce Latin America's ability to attract fragmented production.

We examine this question by performing an analysis of global data on multinationals using the Worldbase dataset that we introduced in Chap. 2. In our analysis we assess whether countries with inadequate logistics systems attract fewer vertical affiliates. We start by showing a very simple association between the share of countries'

\footnotetext{
${ }^{4}$ Our port infrastructure variable consists of the number of ports in the country that have lifts with leverage capacity of at least 50 tons (squared), normalized by the country's population. The data on port characteristics come from the World Port Index, 2011, prepared by the US National Geospatial-Intelligence Agency. In an alternative version we normalized by using the country's employment, which yielded similar results.

${ }^{5}$ The measure consists of the number of airports with paved runways at least 2,000 $\mathrm{m}$ long and $40 \mathrm{~m}$ wide (squared), divided by the population of the country. This choice of runway dimension is based on the minimum requirements of aircraft typically used in the air cargo industry (see Micco \& Serebrisky, 2006). The data on airport characteristics come from the ST3400 Database, 2011, of Sandel Avionics. In an alternative version we normalized by the country's employment, which yielded similar results.

${ }^{6}$ This partnership was created in 2003 by ITU, OECD, UNCTAD, UNESCO Institute for Statistics, UNECA, UNECLAC, UNESCAP, UNESCWA, the UN ICT Task Force, and the World Bank, to work towards defining and collecting a set of common ICT indicators and assisting developing countries in their efforts to produce information statistics. The data come from the ITU World Telecommunication/ICT Indicators 2011.

${ }^{7}$ The core indicators are fixed telephone lines per 100 inhabitants, mobile cellular telephone subscriptions per 100 inhabitants, terrestrial mobile wireless subscriptions per 100 inhabitants, dedicated mobile data subscriptions per 100 inhabitants, fixed (wired) Internet subscriptions per 100 inhabitants, fixed (wired) broadband Internet subscriptions per 100 inhabitants, and the international Internet bandwidth per Internet user.

${ }^{8}$ This is not a new result. Evidence that countries in LAC have lower port and airport productivity measures than other regions has been shown, for example, in Moreira, Volpe, and Blyde (2008) and Pages (2010).
} 


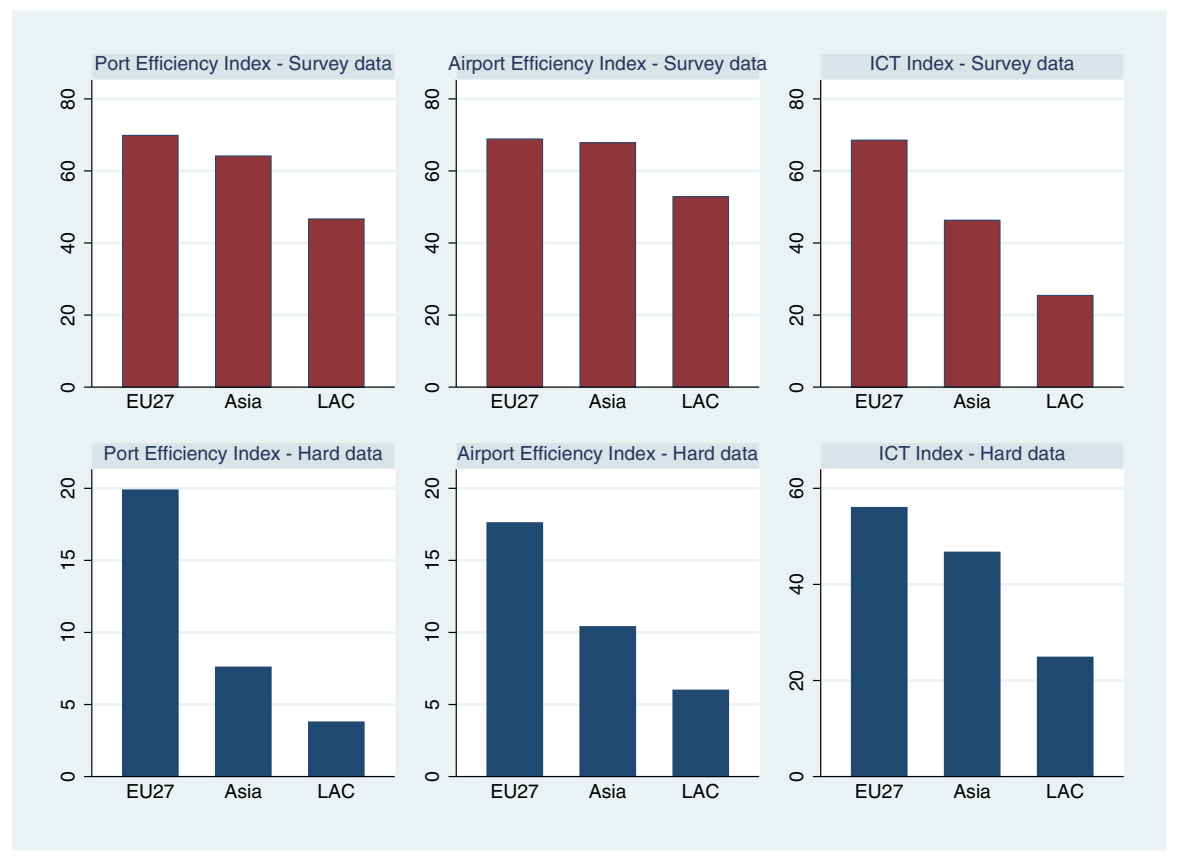

Fig. 3.1 Measures of logistics infrastructure, efficiency indexes, 2012. Source: Authors' calculations

vertical affiliates and the quality of their logistics infrastructure. For the latter we first create sub-indexes that combine the hard data and the survey data for each of the three infrastructure dimensions, and then we take the average of these three sub-indexes. ${ }^{9}$ Figure 3.2 divides the countries in the sample into four groups (or quartiles) according to the quality of their logistics infrastructure. The first quartile corresponds to the countries with the least adequate logistics infrastructure, and the fourth quartile corresponds to the countries with the best quality infrastructure. It is immediately clear that the higher the quality of logistics infrastructure, the larger the share of vertical affiliates. For instance, the countries in the fourth quartile have $75 \%$ of the vertical affiliates in the entire sample, while the countries in the first quartile have less than $1 \%$.

We can gain further insights by examining the dependence of industries on good logistics services. We can see, for example, that some industries are more sensitive to shipping times than others (Hummels \& Schaur, 2012), particularly for the

\footnotetext{
${ }^{9} \mathrm{We}$ create a port infrastructure index that consists of the average of the port measure constructed with the hard data and the port measure constructed with the survey information after each measure is normalized to take values from 1 to 100 . Similarly, an airport infrastructure index and an ICT infrastructure index are constructed by combining their corresponding hard data and survey indexes. Finally, an overall logistics index is constructed that consists of the average of the three sub-indexes.
} 


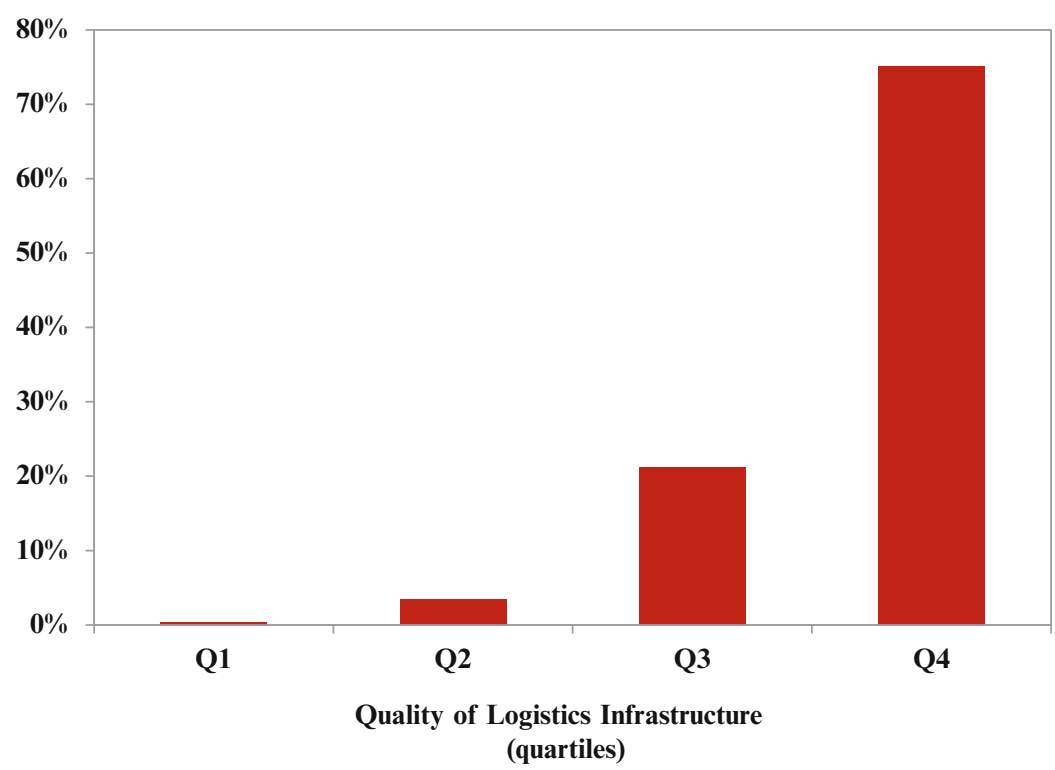

Fig. 3.2 Share of vertical affiliates by quality of logistics infrastructure. Source: Authors' calculations

movement of intermediate inputs in a global supply chain. For example, a major challenge for a supply chain for computer components is their rapid depreciation; therefore, components in such production networks must move rapidly along the chain, which requires logistics systems that can handle fast deliveries. A recent study on offshoring found that rapid supply of local markets was the most important decision driver in the development of a manufacturing sourcing strategy in the consumer electronics industry (Hackett Group, 2012). According to the study, highly dynamic industries with short product life cycles and high levels of demand variability base their decisions about where to locate on the quality of transportation and logistics. However, the study found that rapid delivery of components is much less important in the supply chains of less dynamic but highly price-sensitive industries, such as furniture manufacturing. For these industries, raw material and component costs are much more important factors driving the location decision than the quality of the logistics infrastructure.

To proxy for the dependence of the industry on logistics services, we employ a measure of industry sensitivity to shipping times constructed by Hummels and Schaur (2012). The rationale is the idea that rapid delivery requires good logistics infrastructure; therefore, industries that are sensitive to shipping times are also sensitive to good logistics services. The measure is based on the premium for air shipping that firms in an industry are willing to pay to avoid an additional day of ocean transport. ${ }^{10}$ It is interesting to note that since the measure is constructed to be agnostic regarding

\footnotetext{
${ }^{10}$ The measure is calculated for more than 1,000 products at the four-digit level of the Harmonized System (HS).
} 


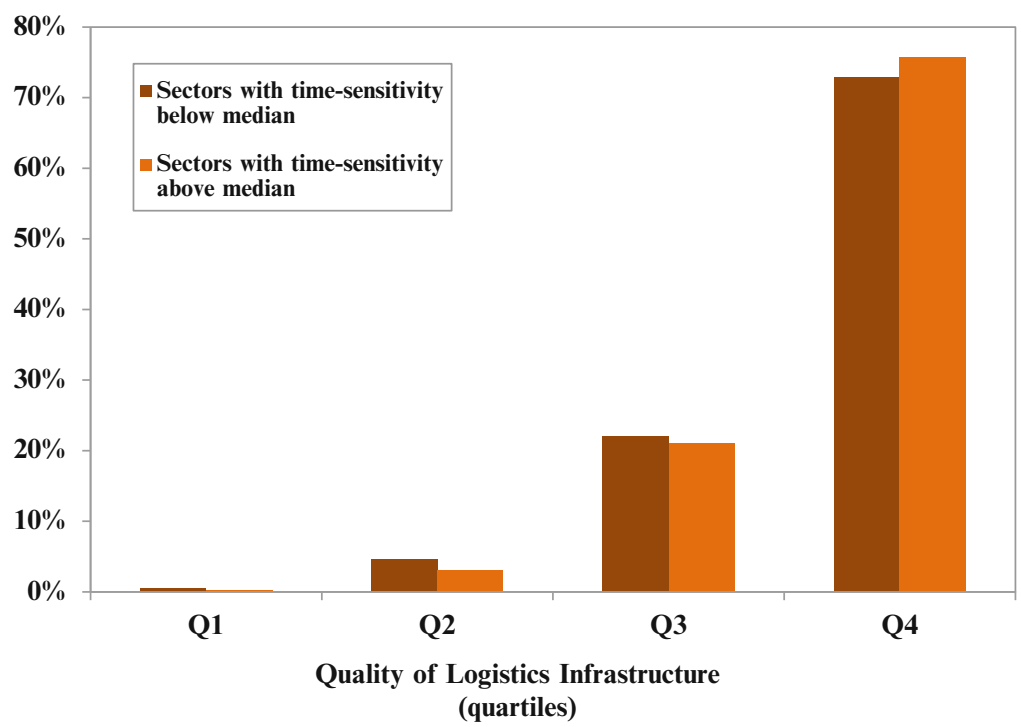

Fig. 3.3 Share of vertical affiliates by quality of logistics infrastructure and dependence on logistics services. Source: Authors' calculations

the importance of speed, it can capture dependence on logistics services for a variety of reasons for rapid deliveries — such as the use of perishable goods, goods with short life cycles, or those with high demand variability - and in cases where uncertainty and potential disruptions in the supply chains must be minimized. ${ }^{11}$

Figure 3.3 shows the distribution of vertical affiliates for countries with different levels of logistics infrastructure (as in Fig. 3.2), but in this case the sample is split between vertical affiliates in sectors with values of time sensitivity below the median and sectors with values of time sensitivity above the median. The first aspect to note is that similar to the previous figure, countries with better logistics infrastructure attract more vertical affiliates than countries with inadequate logistics infrastructure. This is observed regardless of the sector: i.e., both sets of columns increase across the quartiles. Another interesting finding is that while both shares of vertical affiliates increase from the first to the fourth quartile, the share in sectors with time sensitivity above the median increases relatively faster. For instance, while countries in the second quartile own more vertical affiliates in non-time-sensitive industries, the opposite is true for the countries in the fourth quartile. This result is interesting because it is telling us that countries with better logistics infrastructure attract not only more vertical affiliates overall, but also, particularly, affiliates in sectors that are more dependent on logistics services.

\footnotetext{
${ }^{11}$ For instance, Hummmels and Schaur (2012) and Evans and Harrigan (2005) examine the link between speed of delivery and uncertainty due to rapid fluctuations in demand. Clark, Schaur, and Kozlova (2012) show that firms tend to switch to more expensive air shipping when uncertainty in ocean shipping increases.
} 
Table 3.1 Expected relationship between bilateral vertical FDI and its determinants

\begin{tabular}{l|l}
\hline Determinants & Expected sign \\
\hline Common border & $(+)$ \\
\hline Common language & $(+)$ \\
\hline Common colonial origins & $(+)$ \\
\hline Distance & $(-)$ \\
\hline Free trade agreement & $(+)$ \\
\hline Skill differential between parent and host country & $(+)$ \\
\hline Quality of logistics infrastructure parent country & $(+)$ \\
\hline Quality of logistics infrastructure host country & $(+)$ \\
\hline
\end{tabular}

Figures 3.2 and 3.3 support the notion that countries with adequate transport and logistics infrastructure attract more vertical affiliates. But while these results are suggestive, they are far from definitive. Countries with good logistics infrastructure could offer additional benefits that would be attractive to vertical FDI. There is also the issue of causality: improvements in logistics infrastructure might attract vertical FDI, but FDI might also spur investments in logistics infrastructure. Therefore, to make a statement on the relationship between logistics infrastructure and international production networks, we need an econometric model that isolates the effect of logistics infrastructure from other factors while simultaneously addressing the issue of causality. For this purpose we employ an augmented version of the empirical workhorse model in international trade, the gravity equation.

A complete description of the model and its estimation is provided in Appendix B "Specification for the Model of Vertical FDI and Logistics Infrastructure". Here we present the basic intuition of the quantitative analysis. Table 3.1 summarizes the expected signs of all the variables included in the model. In essence, vertical FDI, and thus trade of intermediate inputs between a subsidiary and its headquarters, should be larger between countries with common borders, a common language, common colonial roots, shorter distances, lower trade barriers, larger skill differentials, and higher-quality logistics infrastructures in both countries. ${ }^{12}$ The analysis also employs techniques that control for additional variables at the country and sector level that might influence vertical FDI but are not observed by the econometrician. ${ }^{13}$

The dependent variable in the model is the number of vertical affiliates located in host country $i$ from parent country $j$ and sector $k$. The dataset is for the year 2012. One interesting aspect of the empirical analysis is that we also formally test the proposition that countries with adequate logistics systems may attract more vertical

\footnotetext{
${ }^{12}$ We proxy the skill differential by the ratio of the parent country's skill to the host country's skill, where country skill is the average years of schooling in the population of age 25 and above. Alfaro and Charlton (2009) also use the average years of schooling to proxy for human capital abundance.

${ }^{13}$ These are country and sector fixed effects. See appendix B "Specification for the Model of Vertical FDI and Logistics Infrastructure".
} 
FDI in industries that are more dependent on logistics services, as suggested by Fig. 3.2. ${ }^{14}$ The outcomes of the regression are consistent with the expectations. Even after controlling for the effect of alternative factors, the results indicate that countries with better logistics infrastructure attract more vertical affiliates, particularly in industries that are more dependent on logistics services. As shown in the appendixes, this result holds under alternative estimation techniques and control variables. ${ }^{15}$ The magnitude of the effect is economically meaningful. We find, for instance, that a change from the first quartile to the third quartile of the distribution of logistics infrastructure is associated with an average increase in the number of vertically integrated affiliates equivalent to $15 \%$.

We also explore whether the importance of logistics infrastructure tends to increase with distance. One can reasonably assume, for instance, that differences in time sensitivity across industries might be less relevant for countries that are very close to each other, because products can be delivered quickly. But when countries are far apart, these differences should matter more. Results in Table B.1 (in Appendix B "Specification for the Model of Vertical FDI and Logistics Infrastructure") confirm this assumption: the importance of adequate logistics infrastructure, particularly for logistics-sensitive industries, increases with distance. In other words, for distant countries to attract more vertical FDI, issues such as improving port or airport efficiency are likely to be more important in offsetting the impact of distance than for nearby countries. This result is relevant for Latin American countries. For example, the average bilateral distance across all the East Asian + ASEAN countries is about $2,400 \mathrm{~km}$, while the average distance across the countries in Latin America is $3,000 \mathrm{~km}$. If we include the US and Canada, the distance across the Americas is 3,200 km, or $30 \%$ more than in Asia. In the case of the EU-27, the average bilateral distance is a mere $1,400 \mathrm{~km}$. Therefore, geography imposes a challenge when countries in Latin America seek to join distant supply chains in Asia or Europe, or even to develop supply chains within their own region. What the econometric results suggest is that the issue of logistics infrastructure should be, if anything, relatively more important for Latin America than for other regions, whose countries tend to be closer to each other.

\footnotetext{
${ }^{14}$ Indeed, this test addresses the potential causality issue mentioned earlier. In particular, the test implies examining a cross-country, cross-sector interaction effect, the so-called difference-indifferences estimation. The estimation seeks to alleviate the potential endogeneity problem associated with cross-country regressions. The difference-in-differences estimator would suffer from reverse causality if the FDI flow of a given sector compared to those of other sectors had a causal effect on the overall level of logistics infrastructure. This seems much less likely to be the case than in the more common cross-country regressions, in which total FDI flows could have a causal effect on the overall level of logistics infrastructure investment.

${ }^{15}$ In particular, Appendix B "Specification for the Model of Vertical FDI and Logistics Infrastructure" shows that the main finding holds under least squares and negative binomial estimations, as well as after the inclusion of parent, subsidiary, and sector-fixed effects, and under the more stringent parent-subsidiary, sector-fixed effects. In a longer version of this analysis we also show that the results are sufficiently robust to explicitly include additional covariates in the model; see Blyde and Molina (2013).
} 


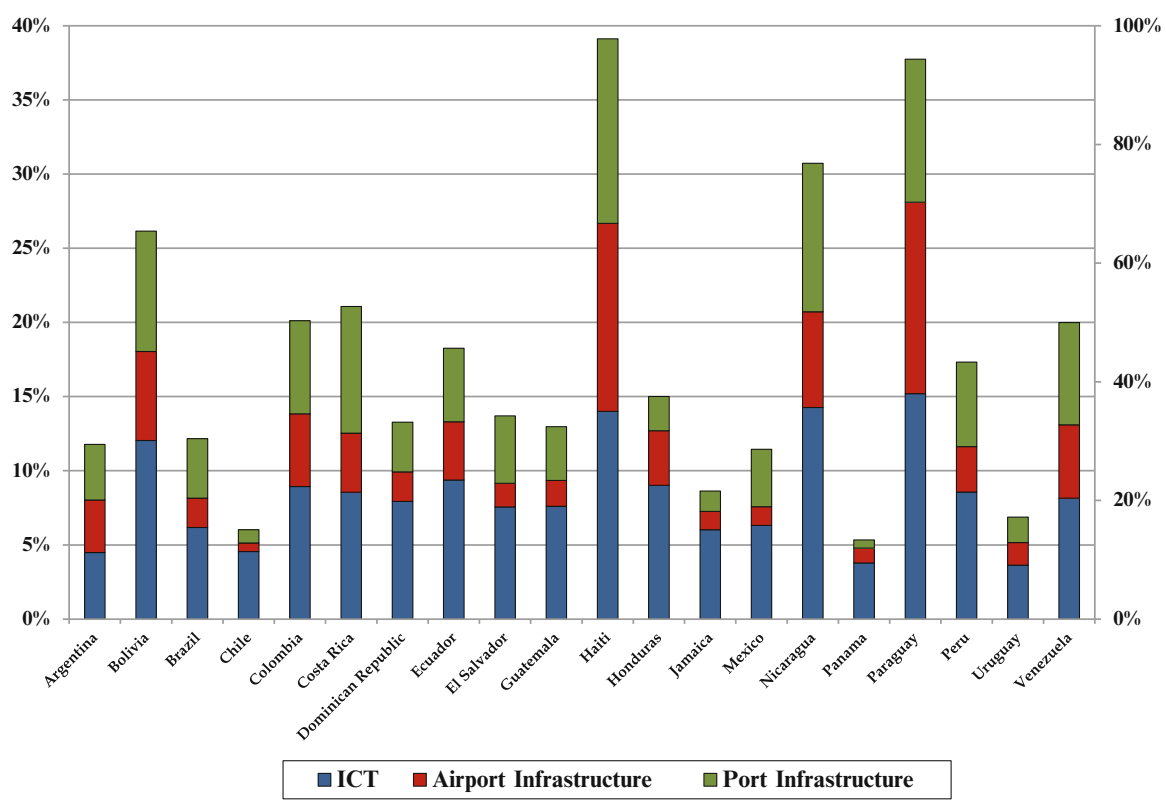

Fig. 3.4 Simulated change in the number of vertical affiliates from improving logistics infrastructure to the EU-27 average. Note: The values for Haiti are represented on the right axis. Source: Authors' calculations

We now use the results from the estimations to simulate the impact of improving the quality of logistics infrastructure in the region. In particular, we ask by how much the particular measure of value chain participation would increase if a country in LAC improves the quality of its logistics infrastructure to the average level in the EU-27. We do this for each of the infrastructure dimensions that comprise the overall index: port, airport, and ICT infrastructure. The results for the number of vertical affiliates are shown in Fig. 3.4. ${ }^{16}$ Since most countries have important gaps in all three infrastructure dimensions, closing any of these gaps generates noticeable surges in vertical FDI. On average, the number of vertical affiliates would rise by around $20 \%$; countries with more important shortcomings in logistics infrastructure, such as Haiti or Paraguay, would experience much larger increases.

The results in Fig. 3.4 presented the average increase in the number of vertical affiliates across all the sectors of the economy. Figure 3.5 shows the results of the same simulation when we look only at the sectors with time-sensitivity above the median. The figure indicates that the number of vertical affiliates in these sectors increases even more than before, with an average of $28 \%$ for the entire region.

\footnotetext{
${ }^{16}$ We use the results from column 3 in Table B.1 (see Appendix B "Specification for the Model of Vertical FDI and Logistics Infrastructure").
} 


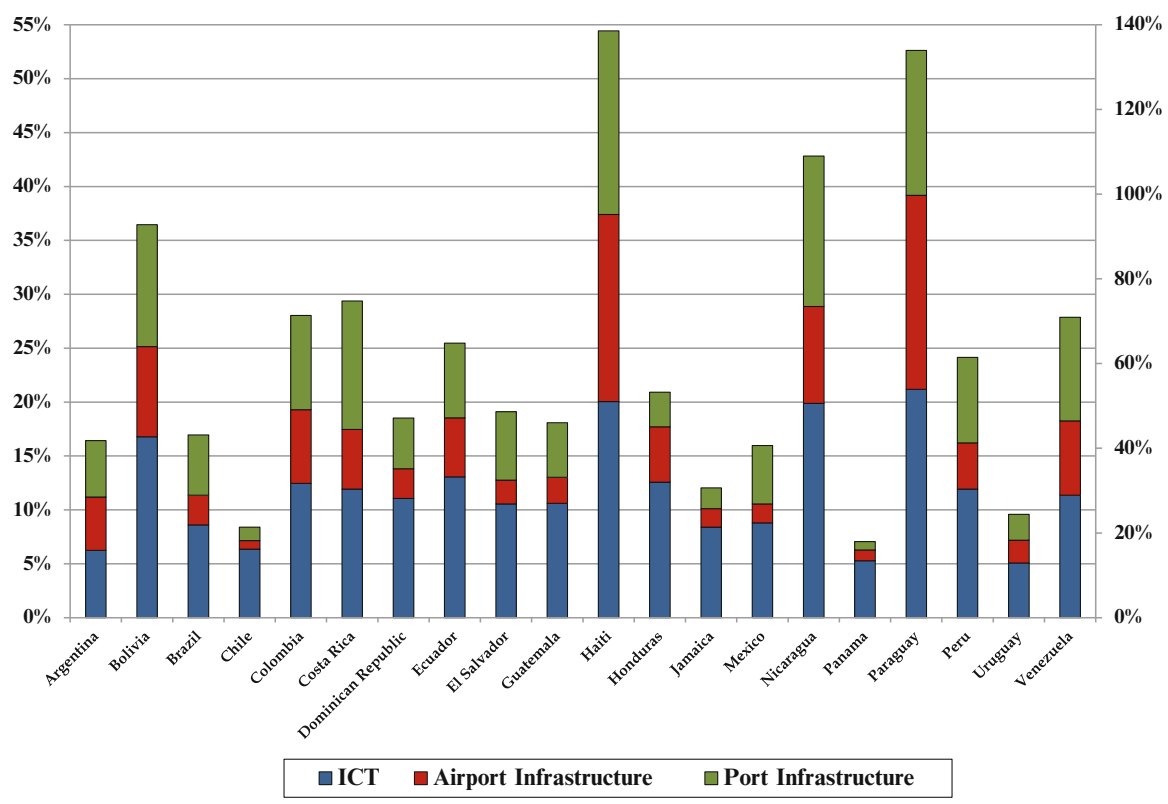

Fig. 3.5 Simulated change in the number of vertical affiliates in sectors with time-sensitivity above median from improving logistics infrastructure to the EU-27 average Note: The values for Haiti are represented on the right axis. Source: Authors' calculations

\section{Policy Issues}

Improving a country's transportation and logistics systems requires that an array of issues be addressed, from the quality of the infrastructure to the efficiency of related services. While a detailed description of the required policies is beyond the scope of this work, a few general issues of particular importance for production networks should be stressed. Box 1 further provides specific examples from case studies in Latin America in which logistics has been fundamental for enabling firms to join or develop supply chains.

With respect to maritime transportation, countries in Latin American and the Caribbean have come a long way since the days of heavy state intervention. Cargo reserves for state-owned shipping companies have been mostly eliminated, and maritime shipping services have generally been liberalized. In addition, many national ports and terminals have granted concessions to private port operators. One result has been to trigger a wave of modernization in many port infrastructures, including the installation of gantry cranes for faster loading and unloading and electronic tracking of containers to reduce waiting and turnaround time for ships. Although these improvements have been a critical factor for many supply chains, the productivity of Latin American port infrastructure remains far from world-class. A rare dataset available for a selected group of ports, for example, shows that when 


\section{Box 1: The Role of Logistics}

This box presents two case studies in which logistics policies facilitated the spread of global supply chains.

Bombardier Querétaro. During the 1970s, the world aeronautic industry was vertically integrated, with only about $20 \%$ of the typical aircraft manufacturer's total value being outsourced. Today, that outsourced share is close to $80 \%$. Mexico is taking advantage of this trend by spurring the development of an aeronautic cluster, mainly centered in the state of Querétaro. The aim is to attract global firms and support linkages between them and Mexican suppliers.

One of the foreign firms attracted to Querétaro was Bombardier, the Canadian aircraft manufacturer. Cost advantage, proximity to the US and Canada, and the free trade agreement among Mexico, Canada, and the US (NAFTA) were among the pull factors for Bombardier. But these incentives were complemented by a series of logistics developments, such as large investments in the Querétaro airport. With specialized warehouse services and one of the longest runways in the country, the airport sits at the convergence of Mexico's road, rail, and telecommunications network, thereby facilitating multimodal operations and allowing Bombardier to ship parts to Wichita and Toronto for assembly much more quickly than if they had been produced in China. In fact, Bombardier's plant is located within the perimeters of this airport.

Bombardier was attracted to the cluster by the massive transport infrastructure investments made by the state government. Nevertheless, a number of logistics issues also needed to be addressed to guarantee smooth operations of the company's supply chain. For instance, when Bombardier started its operations in Mexico, the federal customs office was located in downtown Querétaro, not at the airport. The authorities initially insisted that every component be brought from the airport to downtown for customs clearance, and then shipped back to the airport, where the Bombardier factory is located. This extra step increased time and costs for customs clearance. Eventually, the federal government established a customs area at the airport.

Another soft policy measure was the signing of the Bilateral Aviation Safety Agreement with the US, which allows Mexico's civil aviation authority to certify parts and components produced in Mexico. This development essentially eliminated one step in the supply chain, which considerably reduced costs and time because components and parts no longer had to be inspected in the US before being shipped off to the assembly locations.

Basso. Since the 1990s, the automotive industry has become more global with the growing importance of FDI in developing countries during recent years. This shift in global production resulted from a significant organizational change in which the Ford model was replaced by the Toyota model, which prioritizes production flexibility, quality, and speed. Assemblers started delegating more design responsibilities to component suppliers, urging the latter to supply them with efficient technological solutions.

(continued) 


\section{Box 1: (continued)}

One of these component suppliers is Basso, a producer of combustion engine valves, located in Rafaela, Argentina. The firm makes valves for automakers (e.g., Peugeot, Ferrari, and Ford), motorcycle producers (Harley Davidson), and farm tractor producers (John Deere).

Basso has been able to compete globally due to its high-quality customization of products and a strict commitment to provide just-in-time delivery services, the demanding mode of production that became widespread with the emergence of the Toyota model. Logistics is key to the firm's business, and its just-in-time delivery service-which coordinates storage, transport, and inventory-is one of the firm's main distinguishing features.

Complying with just-in-time shipment commitments is not easy, however, particularly when about half of the company's clients are located more than $8,000 \mathrm{~km}$ away. Basso orchestrates a logistical system that makes customers feel that such long distances are not relevant.

One change that was fundamental to the company's ability to fulfill its delivery commitments was the creation of an Argentine customs office in the city of Rafaela, a move that resulted from joint action by businessmen and city officials. The new customs office enables Basso to clear every export and import operation in Rafaela without the need to do so at the Port of Buenos Aires. Since the valves that are shipped from Rafaela already have customs verification and approval, delivery is much more rapid.

Despite these advances, the company must still plan for possible logistics problems, such as roadblocks or strikes at the ports. For example, the firm maintains a permanent stock of goods on ships and in warehouses, a practice that increases its inventory costs. As such, while the firm benefits from facilitated customs clearance, it incurs other costs in dealing with uncertainty in logistics.

The examples of Bombardier and Basso illustrate that creating an adequate logistics system is not only about big physical infrastructure works, but also about the less visible but perhaps equally important soft policies related to logistics.

Sources: the story of Bombardier is based on material from Brown-Grossman and Domínguez-Villalobos (2012) and remarks by Michael R. McAdoo, Vice-President of International Trade, Bombardier, at the 2012 World Economic Forum on Latin America. The case of Basso is based on material from González, Hallak, Schott, and Soria (2012).

measured in terms of TEU per meter of quay, ${ }^{17}$ the average productivity for ports in South East Asia is almost three times higher than the average productivity in Latin American ports (Drewry, 2010).

\footnotetext{
${ }^{17}$ The maritime literature frequently uses this performance indicator for container terminals. The measure means the number of 20 -ft-equivalent unit containers handled per running meter of quay per year.
} 
Latin American countries seeking to participate in global production networks must therefore continue to pursue reforms that improve the productivity of their port infrastructure and increase the efficiency of their ancillary services, such as cargo handling, storage, and warehousing.

In addition to the liberalization of the industry and the decentralization of port operations, there are many other areas in which the government should play an active role. For instance, government must create effective regulations that assure proper market contestability to prevent anticompetitive practices by carriers and shipping companies (Sanchez \& Wilmsmeier, 2009). In addition, government must make investments, such as channel dredging, to enable larger vessels with lower operating costs to enter a port; such investments might not take place without government intervention. Increasingly larger vessels that travel at higher speeds are constantly being introduced. The largest vessels currently in use (average 13,000 TEUs) are expected to start serving the region within the next 5-8 years (CEPAL, 2012). Accommodating these vessels may require new plans and strategies for port industries and related activities in many countries of the region (CEPAL, 2012). An important step in this direction is the expansion of the Panama Canal. Completion of the new set of locks and ancillary projects (dredging and widening), will enable the canal to handle containerships of 13,000 TEUs.

As with port infrastructure, airport efficiency has improved as a result of a gradual shift from the traditional public ownership model to arrangements that include alternative privatization schemes and concession contracts. With the exception of a few services, such as meteorological services, most commercial and handling operations can be provided on a competitive basis. Airport privatization throughout the world has generally led to improvements in efficiency, but privatization in Latin America has proceeded at a slower pace than in many other parts of the world, particularly in the Asia-Pacific region and in industrialized countries (ACI, 2008). Additionally, transfer of ownership has not always resulted in improved efficiency, due to lack of market contestability. Governments in the region must enact regulatory frameworks that ensure competitive conditions for ancillary services (Serebrisky, Schwartz, Pachón, \& Ricover, 2011).

Meeting the demands of global supply chains also requires a liberalization of the region's international air services. In other parts of the world, many firms engaged in production networks can choose among multiple carriers because of more open air transport markets. For example, an airline's right to carry cargo from its own country to a second country, and from that country to a third country - the so-called "fifth freedom"-is instrumental for many supply chains. With manufacturers demanding inputs from multiple suppliers, the fifth freedom gives carriers the needed flexibility to serve multiple nodes.

In Latin America and the Caribbean, air services are still restricted by old bilateral agreements that put stringent limitations on market access. For example, while many agreements grant fifth freedom rights, there are usually maximum capacity thresholds, and passengers generally receive preference over cargo. 
Efforts should be made to remove these maximum thresholds. At a broader level, the region must do more to move in tandem with liberalization efforts in other parts of the world, most of which have been carried out through open skies agreements. For example, it has been shown that open skies agreements signed by the US have reduced air transport costs by around $9 \%$ while increasing the share of imports arriving by air by $7 \%$ (Micco \& Serebrisky, 2006). A movement towards a regional open skies agreement in Latin America and the Caribbean would certainly lower the costs of connecting suppliers and buyers in various points of the region's supply chain.

Policy issues also must be addressed to improve the region's ICT infrastructure. Prior to the waves of privatization during the 1990s, prices in the telecommunication sector did not reflect the true costs for providing the services; there were no incentives for innovation, and services were generally of low quality (Razo \& Rojas Mejia, 2007). The privatization of the state monopolies brought about more innovation and generally increased efficiency in the provision of services (Aguerro \& Mastrini, 2009; De Laiglesia, 2007). However, the liberalization did not automatically result in increased competition. Many countries, for example, granted exclusivity periods to allow companies to invest in infrastructure upgrading and installation so as to consolidate their position in the market. Such exclusivity periods strengthened the dominant position of the incumbent firms and created incentives to set high prices and prevent access to new services (Razo \& Rojas Mejia, 2007). The long periods of exclusive operation granted to the initial investors significantly delayed the entry of new providers and obstructed the creation of competitive markets.

Furthermore, the ICT legal frameworks and regulatory agencies that were put in place years ago have not proved themselves capable of encouraging competition and dealing with the challenges of the sector. For example, firms today commonly offer packages that combine different types of services. This new trend creates a challenge for the regulator, who must determine the relevant market definition on which to base judgments about anticompetitive behavior (Aldana \& Vallejo, 2010; Rozas, 2002). The main challenges in the telecommunication sector today are to reduce the high levels of market concentration and create conditions for the development of competitive markets. The constant evolution of the sector requires the regulator to continuously adapt to deal with these challenges.

The econometric exercise in this section explicitly modeled the role of critical air, maritime, and ICT infrastructures. However, although these infrastructures are important pieces of a country's logistics system, they are not the only ones. Supply chains also require more efficient customs services and streamlined security clearance processes (see Box 1 and also the next section). Likewise, inadequate internal transport-related infrastructure, including the low density and poor quality of many road networks in Latin America, have been shown to negatively impact the region's trade performance. In this area, important policy issues range from placing a new priority on these long-neglected investments to improving regulation of the domestic transport industry. These important subjects deserve to be addressed in separate reports (see, for instance, Mesquita Moreira, Blyde, Volpe, \& Molina, 2013). 


\section{Production Disintegration and Market Integration: Deep Integration Agreements at Work}

How do economic integration agreements affect the formation of international supply chains? Under what conditions do they support production networks among countries? Are trade agreements, and trade policy in general, partly responsible for the lack of participation of Latin American countries in global value chains? This section seeks to provide some answers to these important questions.

Casual evidence and regional studies often suggest that many global supply chains are affected by agreements and/or arrangements between nations. For instance, before the 1965 US-Canada Auto Agreement, trade in auto parts between these two countries practically did not exist. After the agreement was signed and tariff barriers were reduced to 0, a US-Canada auto supply chain was created and auto trade soared (Hummels, Rapoport, \& Yi, 1998). ${ }^{18}$

It is self-evident that tightly integrated countries are more likely to share international production networks. To begin with, crossing borders is always associated with additional costs, such as the tariff duties, which are commonly removed in trade agreements. The impact of removing tariff barriers can be proportionally larger for a production process that crosses borders many times-often the case for many supply chains - than for a final good that crosses borders only once. ${ }^{19}$ Beyond the issue of tariffs, establishing production networks across countries may involve a mix of flows related to trade, investment, and technical knowledge, whose maximization requires the close collaboration of the parties involved. For instance, offshoring from an affiliate involves making cross-border investments that might not take place without adequate investment rules in the host country. Similarly, engaging in contract manufacturing with local suppliers typically requires a flow of knowledge that some lead firms may be reluctant to provide without adequate intellectual property rights. Rapid delivery of products, a feature of particular importance for many industries (as observed in the last section), might require harmonizing and streamlining customs and security procedures among the parties involved. In short, complex cross-border activities tend to demand complex rules (Baldwin, 2012).

\footnotetext{
${ }^{18}$ Likewise, Curran and Zignago (2012) show that after the expansion of the European Union in 2004, the new members became a much more important source of intermediate inputs for the old members of the union. Similarly, Karkkainen (2008) shows that flows of FDI from the old EU members to the new members increased to unprecedented levels in the run up to the expansion. The main FDI recipients were Hungary, the Czech Republic, and Poland, the three countries that since then have become crucial parts of the European supply chain. In Asia, the initial growth of production networks may have induced a rising demand for the harmonization of certain national policies across jurisdictions and generally deeper integration, to enable cross-border production networks to operate more smoothly (WTO, 2011).

${ }^{19}$ This notion is formally developed by Ishii and Yi (1997), who show that tariff reductions have a proportionately greater effect on vertical trade involving goods produced sequentially in multiple countries relative to goods produced entirely in one country.
} 
In this regard, deep integration schemes may be associated with more cross-border production sharing because they tend to incorporate disciplines beyond the simple reduction of tariff rates. These disciplines include, among others, rules in investment policy, intellectual property rights, or the harmonization of management techniques in customs procedures to expedite clearance of goods. In short, deep integration agreements tend to create conditions that are likely to be important for global supply chains.

In this section we analyze the proposition that economic integration agreements facilitate the process of fragmentation. In particular, we examine the notion that deep agreements provide greater incentives for the formation of global supply chains than shallow agreements. If integration agreements, particularly deep ones, are closely associated with the formation of international supply chains, two general issues emerge for the countries of Latin America. On the one hand, the prospects of improving the region's participation in extra-regional production networks governed by the countries' respective agreements are likely to remain limited unless membership in those agreements is expanded or their rules of origin are made more flexible; we will examine this issue later in this section. The other issue is related to the multiple trade agreements in Latin America. The countries in LAC are not integrated in one regional trade agreement but share memberships through a complex web of multiple agreements that are likely to restrict the scope of production fragmentation across the region. We will also examine this issue later in this section.

We will first analyze the impacts on GVC participation that one could expect from trade agreements. For this purpose, we use an econometric model that examines the effects of economic integration agreements on a measure of offshoring based on the FDI data introduced in Chap. 2, specifically, the vertically linked subsidiaries. The model estimates the impacts of economic integration agreements on the number of vertically integrated foreign subsidiaries in a pair of host-parent countries in a particular year during the period 1980-2005. It includes a series of variables that control for time-invariant country-pair characteristics (such as bilateral distance) as well as for host and parent characteristics, such as GDP, that vary over time. Details of the model and the data employed can be found in Appendix B "The Effects of Economic Integration Agreements: Estimation and Data Sources".

The results (shown in Fig. 3.6) indicate that economic integration agreements have a positive and significant impact on the number of vertically linked subsidiaries hosted by partner countries. The first bar shows that countries with trade agreements have $8 \%$ more subsidiaries than countries with no trade agreements. The next three bars present the results of an exercise that examines the premise that deep forms of integration induce more cross-border production sharing than shallow trade agreements. For the sake of simplicity, we have grouped the agreements into three types: preferential trade agreements (PTA), free trade agreements (FTA), and deep integration agreements, which cover customs unions (CU), common markets $(\mathrm{CM})$, and economic unions (EU). The figure shows that preferential trade agreements do not have a significant effect on cross-border production sharing. Countries with free trade agreements, however, have $9 \%$ more subsidiaries than countries with no free trade agreements. Finally, countries with deep trade agreements, 


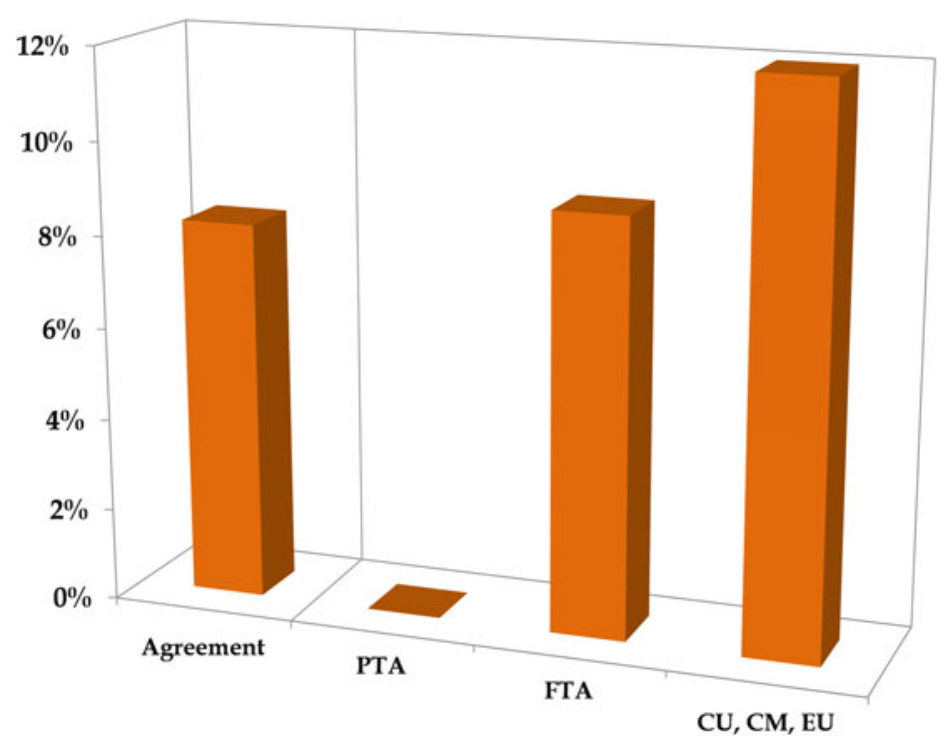

Fig. 3.6 Estimated impact of trade agreements on vertical FDI. Source: Authors' calculations

such as common markets or economic unions, have $12 \%$ more subsidiaries than countries without deep trade agreements. These findings support the notion mentioned earlier that deep integration agreements provide more incentives for the formation of global supply chains than shallow agreements, because they tend to incorporate measures beyond the simple reduction of tariff rates. In so doing, they address a number of dimensions that tend to be important for well-functioning supply chains.

We can probe more deeply into the relationship between trade agreements and vertical FDI by exploring the channels by which trade agreements increase the number of vertically linked affiliates. In our analysis, we wish to determine whether the total increase in the number of subsidiaries is due primarily to an increase in the number of subsidiaries opened by parent companies or to an increase in the total number of parent companies opening subsidiaries. Likewise, we investigate whether the increase in the number of subsidiaries corresponds to an expansion of the number of subsidiaries in the same sectors or an expansion in new sectors. The results (shown in Fig. 3.7) suggest two things: first, the increase in production fragmentation is primarily due to an increase in the total number of parent companies opening subsidiaries; and second, the increase mainly occurs due to a greater diversification of sectors in which these plants operate.

One issue regarding integration agreements and production networks is that while such agreements may induce the formation of production networks, existing production networks might also generate demand for integration agreements. Such a demand for deeper integration, for example, could take the form of the elimination of technical barriers to trade, which tend to be costly for offshoring (Lawrence, 1996).

In Asia, for example, many regional production networks were developed prior to the acceleration of Asian integration under the ASEAN Free Trade Area and 


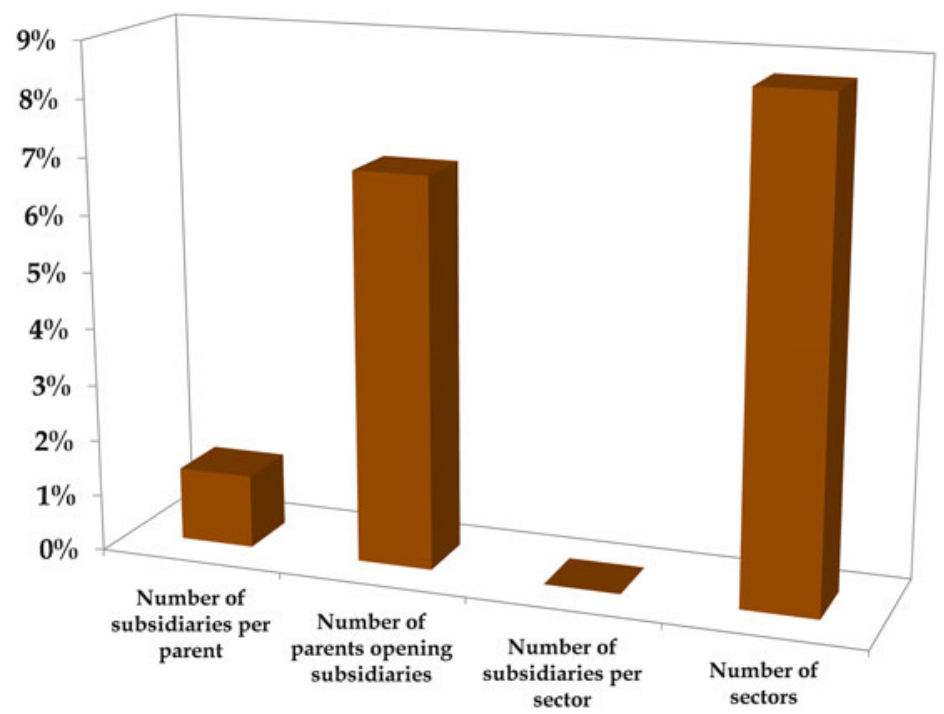

Fig. 3.7 Estimated impact of trade agreements on vertical FDI, by channels. Source: Authors' calculations

under the ASEAN+1 FTAs (Kimura \& Obashi, 2011). Still, many pro-trade and investment policies implemented in Asia may have contributed to this early growth of regional supply chains, such as the aggressive moves to attract FDI that started in the late 1980s, the unilateral trade liberalization periods, the establishment of export processing zones, and, particularly, the low levels of protection for the imports of intermediate inputs, which we will discuss later.

Generally, however, the potential causality from GVCs to trade agreements could introduce a bias in the estimations we presented above. Therefore, we performed a series of tests to examine the possibility of reverse causality. For instance, we included both lagged and lead values of the agreement variable. While the lag values were significant, the lead values were not. In addition, we conducted a placebo exercise by examining whether there was a correlation between current production linkages and future agreements; we found no evidence of such a correlation (see Appendix B "The Effects of Economic Integration Agreements: Estimation and Data Sources" for details). These results indicate that the potential causality from production networks to agreements is unlikely to explain the results presented above.

\section{Policy Issues}

While deep integration schemes are associated with GVCs, it is clear that the multilateral approach would be the optimal way to foster global production networks. As regional trade agreements continue to multiply, a firm seeking to participate in production networks spanning various trade agreements will be hard pressed to 
keep track of all the differences in the governing rules. Similarly, as the production of a good is sliced up across more and more countries, barriers between third countries upstream or downstream become as important as the barriers between the two main partners; they might better be addressed together. But the evolution of the multilateral system has not kept up with modern trends of production fragmentation, and it has yet to provide the policy environment at the global level that international supply chains need to thrive. Instead, countries have used bilateral and regional trade agreements to fill this void.

Trade agreements (TAs), however, can be associated with the well-known problem of trade diversion, the situation in which trade is shifted from a more efficient producer that does not belong to the agreement to a less efficient producer within the agreement.

Another potential risk of TAs is that sometimes they set stringent limits regarding the scope of activities within the supply chain in which the member countries can engage. This was the case with the Caribbean Basin Initiative (CBI), in which the member countries exporting textiles to the US enjoyed tariff-free status in the US, but only for the most basic assembly operations of the textile and apparel industry, mainly sewing. Eventually, the CBI was expanded into the Caribbean Basin Trade and Promotion Act (CBTPA), but even at this point the tariff rate fell to 0 only on products in which the local value added consisted of cut, make, trim, and finishing operations. Not until CAFTA went into effect in 2005 could every aspect of the production process in this supply chain of textiles and apparel, including the use of local yarns, fibers, and other raw materials, be performed in the Central American countries (Pipkin, 2011). This example shows that even though some TAs can open up new prospects for developing countries to participate in cross-border production sharing, this participation may be limited to only a few segments of the supply chain, a practice that could eliminate potentially important opportunities.

TAs may also discourage the utilization of cheaper parts and materials from third countries due to their rules of origin ( $\mathrm{RoO})$. This is particularly the case if these parts and materials are used to produce final goods that are later exported to other members of the agreement. In this sense, RoO could increase production costs to the point where the cost of compliance exceeds the benefit of the preferences conferred by the agreement (Estevadeordal \& Suominen, 2006, 2008). This can be especially problematic for Latin American countries seeking to participate in extra-regional supply chains, particularly in North America, the EU, and Asia.

Of course, RoO are critical parts of many TAs because they establish the conditions that a product must satisfy to be deemed eligible for preferential access in the member countries. They are primarily used to prevent trade deflection-that is, to prevent products from non-participating countries reaching a high-tariff TA partner via the transshipment of the product through a low-tariff TA member. But RoO can severely narrow the choices that firms have for locating slices of their production abroad.

TAs also require that firms deal with the potential complexity associated with keeping track of multiple RoO. When an exporter produces only one good and most intermediate inputs are sourced domestically, the costs of complying with multiple $\mathrm{RoO}$ might not be too large. But when an exporter produces more goods, and the 
sourcing involves many countries, the costs of dealing with multiple origins can be substantially greater. These costs may increase even more if the suppliers are not wholly owned affiliates but rather independent firms in other countries. In this case, transparent channels for conveying the supplier's origin information, such as pricing and other sensitivity issues, are less likely to exist. For instance, suppliers might lack sufficient incentives to provide their clients with complete sourcing information for fear that this might jeopardize their relationship; the client might then make direct contact with the subcontractor and cut the supplier out of the chain (Staples \& Harris, 2009).

The question is how to better align the legitimate practice of curbing trade deflection with the reality of GVCs. The constraints generally presented by RoO, can be reduced through the use of various mechanisms, such as higher de minimis levels, allowing for duty drawback, or flexible cumulation rules.

De minimis rules, for example, allow for the use of a specified percentage of non-originating products in the production process without affecting the origin status of the final product. Duty drawback is used to return the payment of applicable duties to the non-originating material employed in the production of a final product that is subsequently exported to other members of the agreement.

Finally, cumulation generally means that inputs from trading partners can be used in the production of a final good without undermining the product's origin. Practically all TAs permit bilateral cumulation, meaning that materials originating in any one member country are considered as originating in the partner country and vice versa. In agreements among more than two countries this is sometimes called diagonal cumulation. Full cumulation means that any operation performed in any of the partner countries can be counted, whether or not the processing is sufficient to confer originating status upon the materials themselves. Full cumulation is particularly beneficial to the formation of regional value chains, as it allows the various contributions to the final product to be accounted and combined to establish its origin. Additionally, there is a growing trend to employ expanded cumulation to allow three or more countries with separate but overlapping trade agreements to effectively merge their individual bilateral treaties so that inputs can be sourced anywhere within the network. This approach could be the most effective strategy for "multilateralizing" RoO across trade agreements.

Ample empirical evidence suggests that some of these mechanisms can ease constraints imposed by $\mathrm{RoO}$ and generate larger trade flows. The evidence is particularly strong for the role of cumulation schemes (Augier, Gasiorek, \& Tong, 2005; Estevadeordal \& Suominen, 2008; Hayakawa, 2012; Park \& Park, 2009). ${ }^{20}$

\footnotetext{
${ }^{20}$ The evidence is based on different identification techniques. For instance, Estevadeordal and Suominen (2008) and Park and Park (2009) look at the difference in trade flows across groups of country pairs (i.e., differences between members of agreements with diagonal cumulation and members of agreements without diagonal cumulation). Augier et al. (2005) compare trade flows in the same country pairs before and after the introduction of diagonal cumulation. Hayakawa (2012) compares trade flows between the same two countries but under two kinds of schemes-one with bilateral cumulation and another with diagonal cumulation.
} 
All of these analyses show positive and significant trade effects of more flexible cumulation schemes. For instance, Augier et al. (2005) and Hayakawa (2012) show trade creation effects on the order of four to $15 \%$ associated with diagonal accumulation. Even larger effects, on the order of 30-100\%, are found when comparing members in full cumulation schemes to those in bilateral cumulation schemes (Estevadeordal \& Suominen, 2008; Park \& Park, 2009). Therefore, there is a compelling argument in favor of expanding the cumulation of RoOs to reduce the implicit costs faced by active and potential participants of international production networks.

There are signs that countries in many parts of the world are growing more aware of the importance of flexible sourcing schemes. For example, over the nearly 20 years of NAFTA's operation, the agreement has gone through four rounds of changes in RoO that have become progressively more permissive of materials from outside North America. This is clearly good news for other countries in Latin America aiming to enter production networks within the North American hub. Other agreements have similar mechanisms for amending their RoO over time, although as other agreements also learned from the NAFTA experience, they have tended to negotiate less restrictive rules in the first place.

The evidence also shows that reforms have been made that deal with issues such as cumulation. As mentioned before, the existence of multiple and overlapping trade agreements can impose limits on the fragmentation of production across borders. Countries are becoming more aware of the need to eliminate those frictions. Perhaps the most substantial experiment in the expansion of cumulation involved the Pan-Euro-Med cumulation zone. The mechanism that went into effect in 1997 harmonized the RoO provisions of more than ten bilateral EU agreements and enabled cumulation among all of the partners.

One notable Latin American experience of cumulation involved Central America and Mexico. Between 1995 and 2001, Mexico had signed separate agreements with Costa Rica (1995), Nicaragua (1998), and the "Northern Triangle" of El Salvador, Guatemala, and Honduras (2001). These agreements did not provide for cumulation among all six countries and thus had the effect of segmenting value chains that tied the Central American countries to Mexico. For example, chocolates from Costa Rica would not encounter tariff charges in Mexico as long as they were produced entirely in Costa Rica, but the same chocolates would pay a tariff duty if they used cocoa paste from Honduras. In 2011, however, the countries signed a new agreement that enables full cumulation across all six countries under a single set of RoO agreed upon by all parties, giving firms much more flexibility regarding where to source their various inputs. While the Mexico-Central America example is a step in the right direction, a more systemic approach is needed. One bold move would be to promote cumulation of origin across the many bilateral and regional trade agreements in LAC. As a result, firms would be better able to take advantage of the differences in factors prices across locations, resulting in more cross-border production sharing within the region.

In other regions, two negotiations are underway that could have profound effects on the ability of companies to form sophisticated GVCs. The first is the TransPacific Partnership (TPP), which joins 14 countries in a single agreement; members 
include the NAFTA countries, Japan, Peru, Chile, Australia, New Zealand, and four ASEAN countries. Negotiating texts published thus far do not make it clear how the countries intend to structure the cumulation provisions, but it is vital that the structuring be done as broadly and inclusively as possible. If complete cumulation, including all members of the agreement for all products, is not a feature of the TPP, its eventual value will be significantly undermined, especially for supporting the formation of GVCs. Furthermore, since the TPP will include two of the three GVC hubs-Japan and the US - cumulation is needed to exploit complementarities between these hubs.

The second negotiation is the Trans-Atlantic Trade and Investment Partnership between the US and the EU, which aims to eliminate tariffs and seeks regulatory harmonization between the world's two largest economies. In matters of preferential market access, both the US and the EU have large networks of trade agreements with third countries in all regions of the globe. The elimination of bilateral tariffs would erode those preferences. While there is no obligation to mitigate preference erosion, this could be accomplished by explicitly including mechanisms for expanding cumulation to these third parties. Such mechanisms would allow third countries to participate in the GVCs operating in these economies, gaining benefits instead of being sidelined. On this issue, however, LAC countries have very little influence. Nevertheless, where both the US and the EU have already granted duty-free access to materials from many countries in the region, it would seem particularly unreasonable to exclude them from bilateral value chains.

There is also the issue of harmonization of RoO across agreements. Since harmonizing the rules themselves might be quite difficult, countries instead may want to focus on harmonizing the methods of calculating regional value content, as well as on the procedures for certifying and verifying origin. The evidence suggests that differences in these mechanisms and procedures have caused tremendous problems for firms seeking to take advantage of trade agreements. Therefore, the bulk of the gains from $\mathrm{RoO}$ harmonization are likely to be in this area.

Another and more general issue regarding trade policy is related to the protectionist bias that remains in many parts of the world. As we mentioned above, certain trade agreements have been designed to limit the participation of developing countries to only a few segments of the supply chain. This is only a manifestation of a more endemic practice called the tariff escalation problem, in which countries impose low duties on raw materials but higher duties on higher value-added segments of the supply chain. This problem is not as severe as in the past (WTO, 2008), but it still exists. Box 2 shows a very simple example of the MFN tariffs imposed by the countries of the European Union on various segments of the automotive industry. The existing scheme clearly generates disincentives to move beyond the supply of raw materials and into higher value-added segments of the automotive supply chain. Table 3.2 shows that the practice of tariff escalation is not restricted to the automotive sector but rather is widespread across many industries.

Many countries, including developing nations, engage in tariff escalation. However, since the industrialized world leads most of the international supply chains, tariff escalation is particularly harmful for developing countries' participation in 


\section{Box 2: Tariff Escalation in the Automotive Industry}

Following is an illustration of how tariff escalation in developed countries generates disincentives in Latin American countries to upgrade in international supply chains.

Figure 3.8 shows the EU's simple average MFN-applied tariffs for selected products used in the automotive industry, including aluminum ore, a raw material produced in large quantities in the region and used in many vehicle components. A Latin American exporter of aluminum ore would pay no duties to enter the European market. However, a firm in Latin America that uses that aluminum ore to produce pistons for engines faces a duty of $2.7 \%$ to export its pistons to Europe. If instead the firm decides to produce not only the pistons but the entire engine, the European tariff rate will rise to $4 \%$, and if that engine is mounted to a chassis, the tariff increases to $9.1 \%$, and so on. This example illustrates how progressively higher tariffs in the automobile supply chain generate disincentives to move beyond the supply of raw materials and into other segments downstream in the industry.

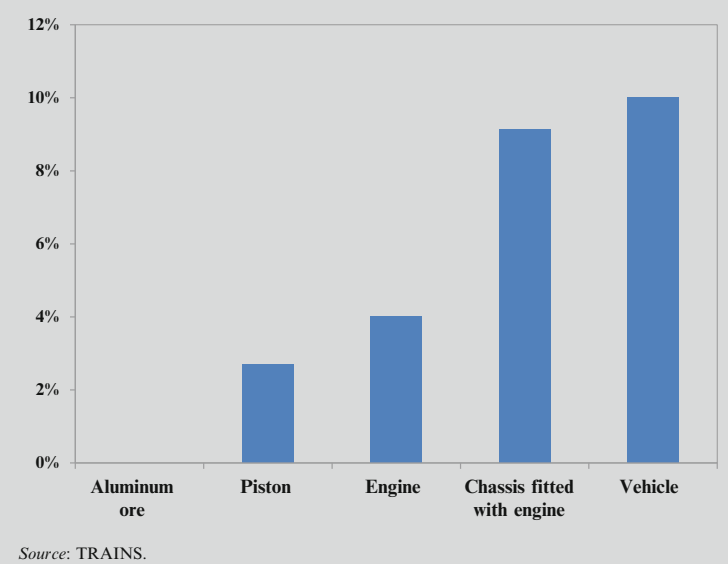

Fig. 3.8 EU average unweighted MFN applied tariff, selected products

supply chains when the practice is employed in the industrial world. This is clearly an obstacle for many firms in Latin America seeking to move beyond the simple provision of raw materials and into other segments of the industrialized world's supply chains.

Another issue related to trade policy concerns the capacity of local firms to complement their production with high-quality inputs from other countries. The emergence of international production networks has indeed strengthened the economic case against import protection, because firms inserted in global supply 
Table 3.2 Average unweighted applied MFN tariffs, 2011

\begin{tabular}{l|l|l|l|l|l|c}
\hline & \multicolumn{4}{l|}{ European Union } & \multicolumn{2}{l}{ United States } \\
\cline { 2 - 8 } & $\begin{array}{l}\text { Raw } \\
\text { materials }\end{array}$ & $\begin{array}{l}\text { Semi- } \\
\text { finished }\end{array}$ & Finished & $\begin{array}{l}\text { Raw } \\
\text { materials }\end{array}$ & $\begin{array}{l}\text { Semi- } \\
\text { finished }\end{array}$ & Finished \\
\hline Fish and fish products & 9.33 & 12.50 & 14.31 & 0.41 & 1.65 & 3.36 \\
\hline Fruit and vegetables & 6.69 & 10.30 & 15.44 & 5.37 & 7.04 & 10.85 \\
\hline Coffee, tea, mate, and cocoa & 3.07 & 8.73 & 9.46 & 0.58 & 0.00 & 5.96 \\
\hline $\begin{array}{l}\text { Mineral products } \\
\text { and precious metals }\end{array}$ & 0.12 & 2.19 & 3.14 & 0.33 & 0.84 & 3.38 \\
\hline Metal ores & 0.00 & 1.57 & 2.81 & 0.09 & 1.18 & 2.00 \\
\hline $\begin{array}{l}\text { Wood, pulp, paper, } \\
\text { and furniture }\end{array}$ & 0.00 & 0.59 & 0.62 & 0.00 & 0.12 & 0.63 \\
\hline Textiles and clothing & 2.98 & 6.57 & 9.73 & 3.47 & 9.40 & 8.52 \\
\hline Leather, rubber, and footwear & 0.07 & 2.43 & 6.00 & 0.00 & 2.02 & 5.60 \\
\hline
\end{tabular}

Source: TRAINS

Note: The table shows the average unweighted applied MFN tariffs in the EU and the US for various categories of products. The tariffs are shown in MTN (Multilateral Trade Negotiation) categories

chains source inputs not only from their own countries but also from other parts of the world. The capacity to export successfully in international markets increasingly depends on the capacity to import efficient inputs. Constraining access to highquality inputs from abroad through high levels of protection may increase production costs and damage the ability of potential suppliers to provide adequate and reliable products in downstream segments of international supply chains. Local content and trade balance measures - the so-called performance requirementsalso force firms (in particular multinational corporations, MNCs) to draw their intermediate inputs from local production, thus limiting their freedom to use imported supplies. ${ }^{21}$ Countries in Latin America will have more opportunities to participate in international production networks when access to foreign intermediate inputs becomes more liberalized.

We will conclude this section by reflecting on the potential scope for developing international production networks as countries become more integrated. The econometric results shown above provide evidence that countries engaging in deep forms of integration tend to share more production processes. But this does not necessarily imply that the production networks must originate exclusively in the countries party to the agreement. Regional integration could also help attract production from outside the region that is subsequently sliced and shared among the countries of the agreement. Hard proof of this argument is difficult to find, but casual evidence suggests that such processes occur more often than expected. An example is found in research by Hiratsuka (2011) and Sturgeon and Florida (2004), who show how multinationals

\footnotetext{
${ }^{21}$ Local content requirements specify the percentage or the absolute value of inputs that must be acquired from local sources or produced domestically. Trade balancing requirements normally limit the imports of the firm to some proportion of the value of its exports.
} 
in the automobile industry source their inputs. Traditionally, subsidiaries of major multinationals located in different countries sourced most of their inputs domestically, except for key components like engines or transmissions, which were supplied by their parent countries. However, this practice has been changing rapidly, and nowhere is this more evident than among the ASEAN countries. Highly incentivized by the ASEAN Free Trade Area, assembly plants located in the ASEAN countries trade large quantities of inputs among themselves. A plant (and its suppliers) in each country tends to specialize in the production of specific components of the car; then each plant exports these components to the other plants of the multinational while importing from them the inputs that are not produced there. Therefore, multinationals from Japan and the US are effectively slicing the production of their cars across various ASEAN countries, taking advantage of their highly integrated space.

This suggests that more regional integration need not be viewed solely as an instrument to develop supply chains originated in Latin America. More regional integration can also attract firms from outside the region and encourage them to establish their supply chains among the Latin American countries.

\section{Production Unbundling and Firm Boundaries: Foreign Affiliates or Local Suppliers?}

Firms planning to fragment production internationally must decide on the degree of control that they want to exercise over the process; as mentioned in Chap. 1, this is called the internalization decision. In this classic make-or-buy decision, the firm chooses either to outsource the procurement of its inputs to non-affiliated suppliers or to engage in foreign direct investment (FDI) and import intermediate inputs from its affiliates. This issue is important for countries wishing to know whether the optimal strategy for improving their participation in production networks should be based on attracting affiliates of multinationals or relying on their local suppliers.

At the heart of this issue is the basic question of why some firms decide to offshore part of their production process to external suppliers while others prefer to employ affiliated plants. Nike, for instance, subcontracts part of its production to independent factories in several countries and keeps only stages, like design and marketing, within the boundaries of the firm. An example of the second form of offshoring is illustrated by General Motors Corporation, which relies on GM affiliates located in different countries to produce specific vehicle components: GM Powertrain-Kaiserslautern in Germany for manufacturing engines, GM Delphi Interior Systems in Mexico for airbags, or GM Strasbourg in France for carburetors, pistons, rings, and valves (Alfaro \& Charlton, 2009).

It could be possible that the type of offshoring that firms choose is an arbitrary decision not based on a particular determinant. However, empirical analyses demonstrate some industry patterns in how firms choose to offshore production. For example, Bernard, Jensen, Redding, and Schott (2010) show that trade between affiliates and headquarters of the same firm (intra-firm trade) accounts for more than $70 \%$ of US imports in industries such as vehicle engines and medical equipment and instruments, 
suggesting that most of the offshoring in these industries occurs through vertical FDI. However, in the rubber and plastic footwear industries, the share of intra-firm trade is only $2 \%$, indicating that offshoring in this case takes place mostly among firms in the US and independent contractors in other countries. The existence of industry patterns suggests that the internalization decision does not occur at random, but is rather a process determined by the interplay of various factors.

If the decision is not random, countries in Latin America should know what these determinants are in order to design strategies to maximize their chances of joining international production networks. For instance, if offshoring in certain industries occurs mostly through affiliates of MNCs, then countries seeking to join production networks in those industries may need to focus on attracting multinationals. But if joining a supply chain is more likely to occur through linking with independent suppliers, as in the case of Nike, then countries should provide support to existing local plants. The general questions then are: Under what conditions should countries wishing to participate in global production networks seek to attract vertical FDI? And under what conditions should they foster their domestic suppliers? This section provides some insights into this important question.

Analysis of this issue requires information on whether offshoring occurs between lead firms and their affiliates in other countries, or between lead firms and independent suppliers. Unfortunately, there are practically no international trade data on transactions identifying the relationship between the supplier and the buyer. A rare exception is the US Related Party Trade database compiled by the US Census Bureau. These data distinguish whether each international trade transaction in the US occurs between affiliated parties or between independent firms. We employ this data in this section. Appendix B "Specification for the Model of Intra-firm Trade" provides more details regarding this dataset as well as the estimations presented in this section.

A cursory look at these data across industries reveals considerable variation in intra-firm imports among industries. Some industries are largely traded between affiliated parties, while others are mostly traded between independent firms. Fig. 3.9, for instance, shows that while imports of electrical equipment, transport equipment, or computer and electronic products exhibit intra-firm shares higher than $50 \%$, the equivalent figures for livestock, leather, and fish products are close to $10 \%$. The results are very similar regardless of whether we consider the imports of all goods or the imports of intermediates only, which is a closer proxy to the goods traded in international production networks. ${ }^{22}$

\footnotetext{
${ }^{22}$ To eliminate the exports of final goods from the total flows of exports we employ the Bureau of Economic Analysis (BEA) 2002 Import Matrix and Input-Output table, which is disaggregated at the six-digit NAICS level. This information shows the share of imports that is used as intermediate inputs and the share of imports that is used for final consumption for each import at the six-digit NAICS level. We multiply the share of imports that is used as an intermediate with the flows of related and non-related party trade to eliminate the exports of final goods in each category. Then, we recalculate the ratio of related to total (related + non-related) exports. The use of I-O tables to separate intermediates and final goods has gained favor in recent years because it avoids the arbitrariness of classification schemes that divide goods into intermediate and other categories, as stressed by Hummels, Ishii, and Yi (2001).
} 


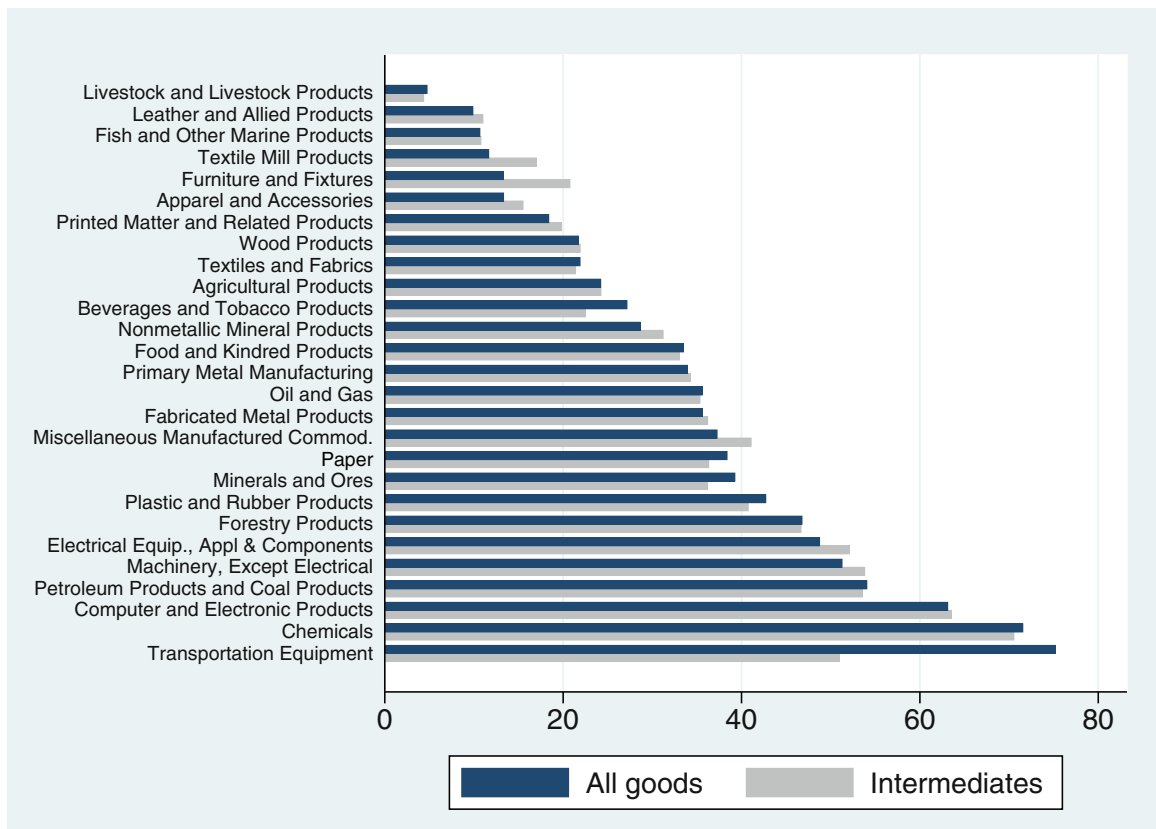

Fig. 3.9 Share of US imports that is intra-firm, by industry (three-digit NAICS), 2010. Source: Authors' calculations based on the Related Party Trade dataset from the US Census Bureau

While the results from Fig. 3.9 suggest that industry characteristics play an important role in the mode by which firms select to offshore their production, other factors might also drive the final outcome. However, it is possible that these other factors are masked by the averages for each industry. In Fig. 3.10, for example, we present an example for a particular industry: electrical equipment, appliances, and components (NAICS 335). Even though in Fig. 3.9 this industry has, on average, a share of intra-firm imports of around $50 \%$, the results from Fig. 3.10 indicate that the share associated with each exporting country varies from 0 to $100 \%$. A similar finding is observed in many other industries. This implies that the mode of offshoring is not completely determined by the industry characteristic. Some country characteristics of the supplier are also likely to play a role. ${ }^{23}$

The evidence presented in Figs. 3.9 and 3.10 indicate two groups of factors that determine the optimal mode of offshoring: those that are intrinsic to the production process (or the industry) and those that are related to country characteristics. Regarding product (or industry) characteristics, it is argued, for example, that the more standardized or codified the knowledge, the greater the chances that the offshoring will occur through independent contractors. Conversely, in highly knowledge-intensive sectors, and in industries where knowledge tends to be tacit

\footnotetext{
${ }^{23}$ Antràs (2014) also shows that US intra-firm shares vary (i) greatly across exporting countries within narrowly defined products and (ii) across products within exporting countries.
} 


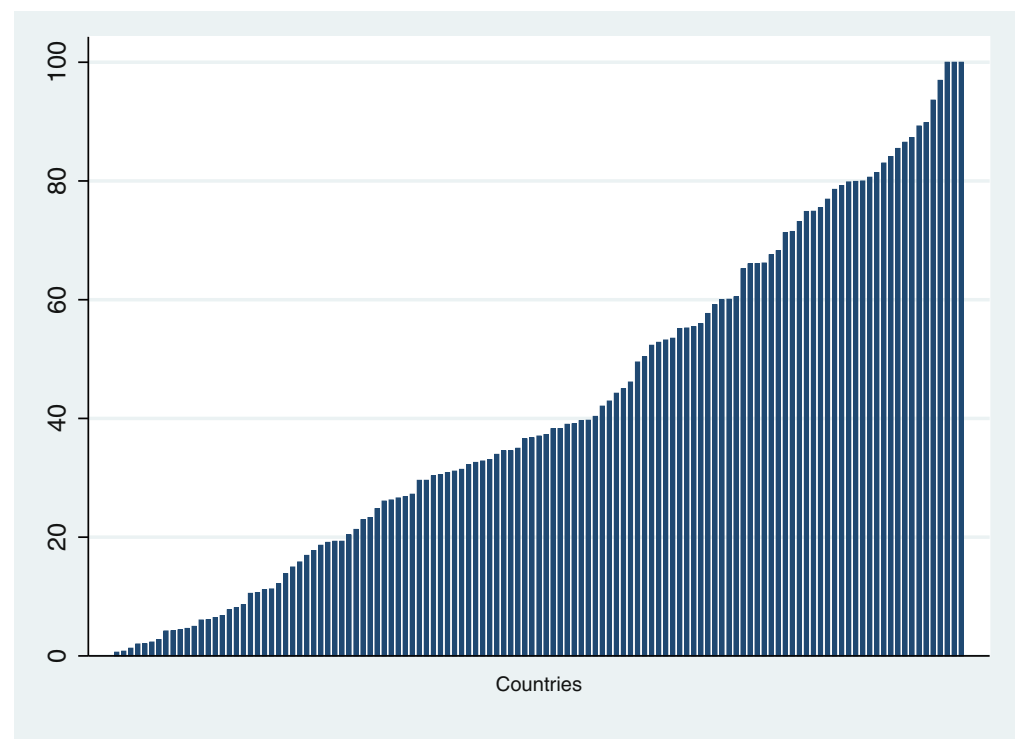

Fig. 3.10 Share of US imports of electrical equipment, appliances, and components that is intrafirm, by country of export, 2010. Source: Authors' calculations based on the Related Party Trade dataset from the US Census Bureau

and difficult to transfer, vertical FDI is more likely to occur. With respect to country factors, it is often argued, for example, that the capacity of the host country to enforce contracts plays an important role in the FDI vs. outsourcing decision. The prevailing view is that if contracts in host countries are hard to enforce, then multinationals have an incentive to internalize activities via vertical FDI to ensure that the parties abide by their obligations. But when the contractual environment strengthens, then outsourcing with external suppliers is more likely to occur.

In the last decade, a growing body of studies has analyzed this particular decision of whether to offshore through affiliates or independent contractors (Antràs, 2003; Antràs \& Helpman, 2004; Antràs \& Helpman, 2008; Costinot, Oldenski, \& Rauch, 2011). A key feature from this literature is that there is indeed a tradeoff between employing independent contractors and opening affiliates, which depends on a complex interaction of factors, some of which are related to intrinsic characteristics of the industry and others to host country-specific factors. ${ }^{24}$

A brief summary of the key aspects of this literature can provide helpful insights. One industry-related aspect that affects the choice between vertical FDI and outsourcing is the factor intensity of the industry. The argument is based on the notion that local suppliers tend to have superior knowledge for hiring and managing local workers.

\footnotetext{
${ }^{24}$ The theory reviewed here is not the only one developed to explain the boundaries of multinational corporations (see, for instance, Buckley \& Casson, 1976). Nevertheless, we focus on the most recent literature dealing with this issue, and particularly related to global supply chains.
} 


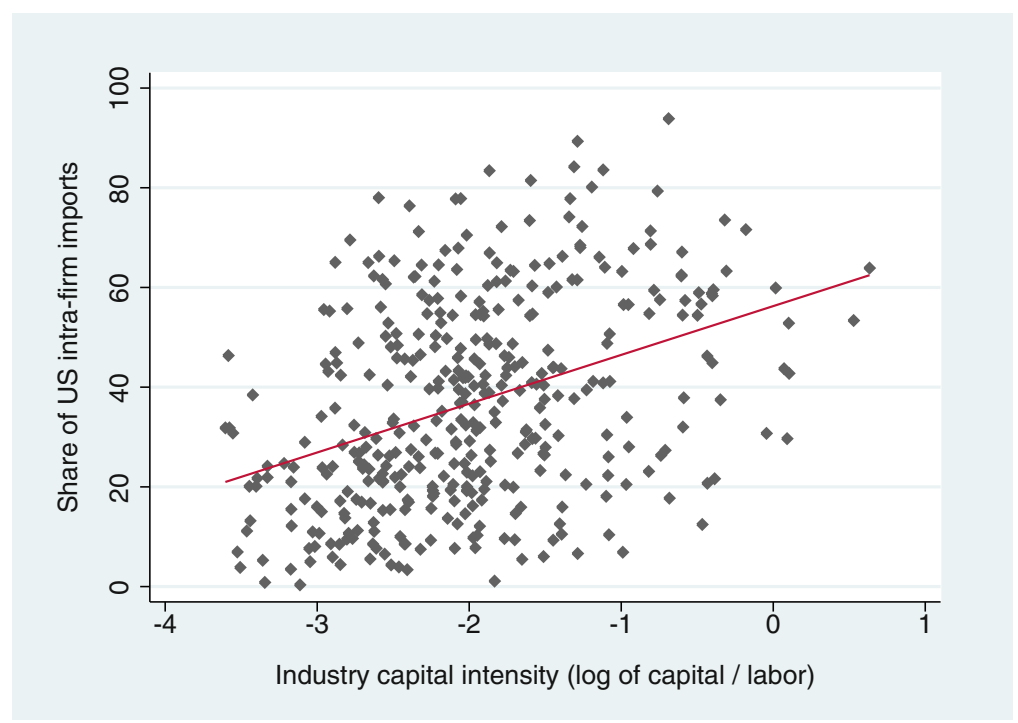

Fig. 3.11 Intra-firm trade and industry capital intensity. Source: Authors' calculations

Therefore, in labor-intensive industries, local management is important, and outsourcing tends to be the preferred choice for offshoring. In comparison, managing workers is a much less challenging proposition in capital-intensive industries, making the importance of local management less relevant. Therefore, in capitalintensive industries, vertical integration is more likely to occur. Figure 3.11 provides some support for this prediction. As shown by the trend line, the share of intra-firm trade is positively correlated with the degree of capital intensity of the industry.

Another factor that affects the choice between vertical FDI and outsourcing emanates from the first aspect and is related to country characteristics. Comparative advantage theory states that capital-abundant countries tend to specialize in capitalintensive industries. If vertical integration is the preferred arrangement for capitalintensive industries, as mentioned above, then capital-abundant countries are more likely to engage in intra-firm trade than capital-scarce countries. Figure 3.12 shows again some support for this prediction. Capital-abundant countries are more likely to engage in intra-firm trade, a positive relationship that is clearly visible in the figure.

Another important factor that influences whether or not offshoring will take place through vertical FDI or through independent firms is related to the nature of the contract between the parties involved. In general, if the product is easily "contractible," then firms fragmenting production internationally can turn to independent suppliers to source their inputs through outsourcing. When the product is not contractible, vertical FDI is favored because multinationals tend to internalize all production activities to ensure that all obligations are met. Again, this is shown in the data. Following Nunn and Trefler (2008), the proxy we use for the difficulty of writing contracts is the proportion of each sector's intermediate inputs that are not traded on organized exchanges or have reference prices; these conditions are likely to give rise to contracting problems. Figure 3.13 indeed shows that industries that 


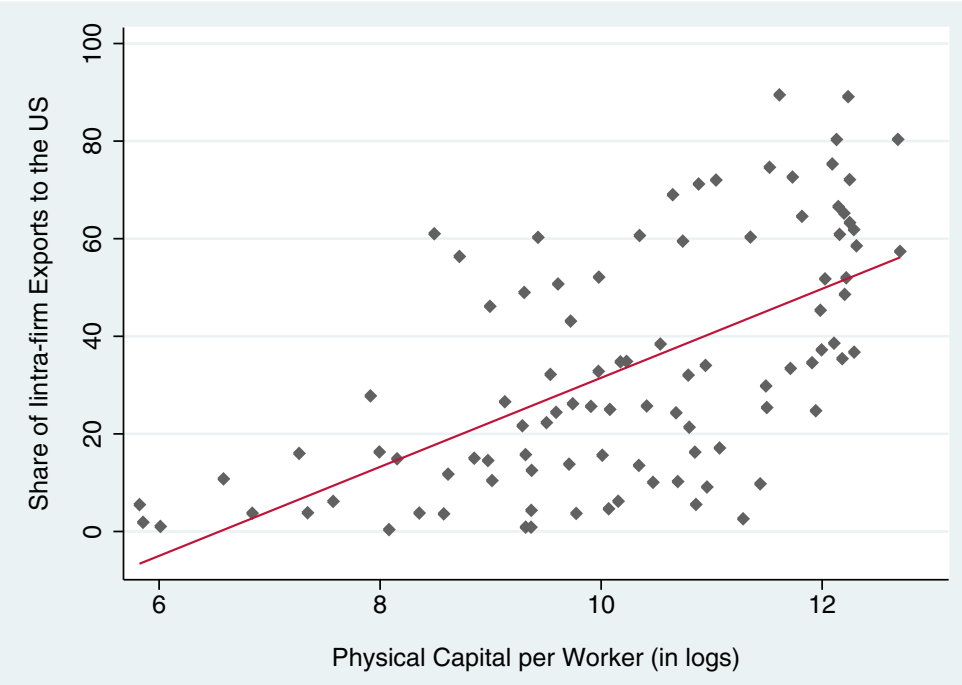

Fig. 3.12 Intra-firm trade and country physical capital. Source: Authors' calculations

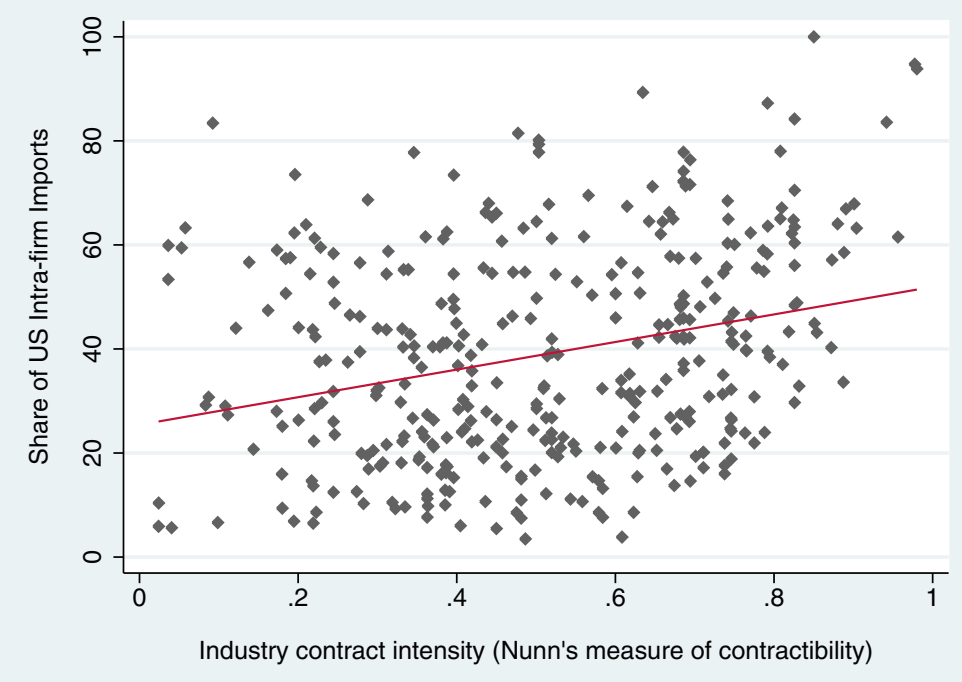

Fig. 3.13 Intra-firm trade and industry contract intensity. Source: Authors' calculations

are more contract intensive (and where contracting problems are more likely to be present) tend to have larger shares of intra-firm trade. In other words, in industries that are more susceptible to potential contracting problems, offshoring tends to occur between affiliated parties and less between independent firms. 


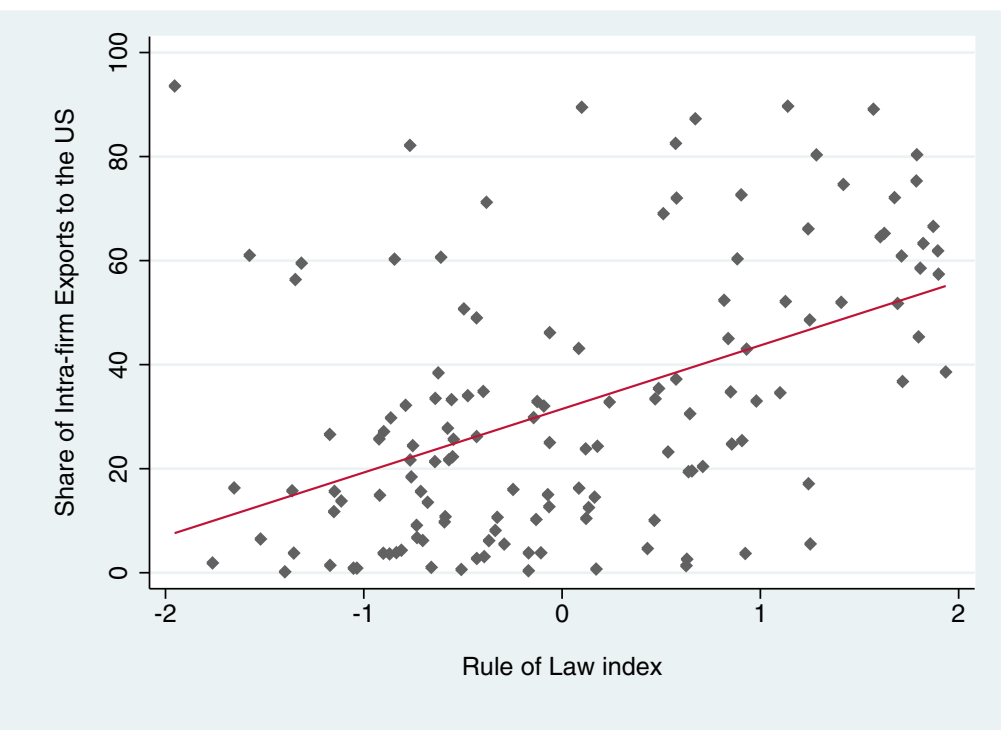

Fig. 3.14 Intra-firm trade and quality of contracting institutions. Source: Authors' calculations

It is important to note that the concept of contractibility depends not only on the characteristics of the good but also on the characteristics of the contracting institutions in the countries. In the first case, a product is contractible when its characteristics make it is easy to write a contract and verify the investments made by the parties. This is the industry-related aspect of contractibility. ${ }^{25}$ In the second case, a product is contractible when it is easy to comply with a contract because the institutions in the country are adequate for doing so; this is the country-related aspect of contractibility.

The general view of the so-called transaction costs literature (e.g., Williamson, $1975,1985)$ on this issue is that improvements in the contractibility environment of a host country tend to trigger an increase in outsourcing instead of FDI, because multinationals can rely more on the local legal system to ensure compliance with the contracts.

In Fig. 3.14 we show the relationship between intra-firm trade and a measure of the quality of the host country's contracting institutions. The figure suggests that countries with better contractual environments export more to the US through intra-firm transactions, which in principle goes against the prevailing view that vertical FDI is the most popular choice to deal with problems of weak contracting institutions. The results of the figure, however, do not test the transaction costs theory, because this

\footnotetext{
${ }^{25}$ Note that changes in technology might impact the contractibility of a product. For instance, it has been argued that many electronics manufacturing processes previously done by hand became automated due to a technological shift. This facilitated the transmission of otherwise complex information and contributed to the rise of contract manufacturing in the electronics industry (Sturgeon, 2002).
} 
correlation might be affected by other factors. As we will show below in a more rigorous analysis, the relationship between the quality of contracting institutions and the mode of offshoring is not as linear as this graph suggests. ${ }^{26}$

While the results presented in Figs. 3.11, 3.12, 3.13, and 3.14 are suggestive, they are far from a thorough examination of the factors affecting the trade-off between vertical FDI and outsourcing. A more formal analysis (presented in Appendix B "Specification for the Model of Intra-firm Trade") is based on a recent body of empirical analyses that examine the drivers of the internalization decision (see Bernard et al., 2010; Carluccio \& Fally, 2012; Corcos, Delphine, Mion, \& Verdier, 2009; Tomiura, 2007). It is worth highlighting several findings from this analysis. First, the results show that, in general, industries that are capital intensive, skill intensive, and not easily contractible tend to be offshored more through vertical FDI, whereas labor- and unskilled-intensive industries as well as industries that are easily contractible are more likely to be offshored through outsourcing. Country characteristics also play a role. For instance, vertical FDI tends to be favored in countries with large physical capital endowments, large size, and adequate market access. These findings tend to support the evidence shown in the above figures.

The second result that should be stressed is that industry characteristics and country factors interact-sometimes in complex ways- to determine the final outcome regarding how offshoring is carried out. We can see this in the issue of contractibility. We have noted, for example, that in industries in which it is more complicated to set up contracts, vertical FDI is more likely to occur, and those industries thus exhibit higher shares of intra-firm trade. This is indeed the prediction of our econometric model, which is indicated in Fig. 3.15 by the positive slope of the blue line. However, as the red line of the figure also shows, the slope decreases in countries with better contracting institutions. In other words, even though vertical FDI is more likely to occur in industries where it is more complicated to set up contracts, this is less the case in countries with good governance. The reasoning is that multinationals can rely more on the local judicial system for compliance with the contracts. The result suggests that offshoring in industries susceptible to contracting problems might initially take the form of vertical FDI, and as contract enforcement improves, local suppliers may become more involved. ${ }^{27}$

\footnotetext{
${ }^{26}$ In principle, it could be argued that the results in Fig. 3.12 support the notion developed recently by Antràs and Helpman (2008) that a better contracting environment in the host country reduces the need to outsource to incentivize foreign suppliers to comply with contracts, thus tilting the balance towards vertical integration. As mentioned in the text, however, the correlation shown in the figure can be affected by many other variables. Therefore, a proper econometric exercise, such as the one shown in appendix B "Specification for the Model of Intra-Firm Trade", is needed to isolate the particular impact of the quality of contracting institutions on intra-firm trade.

${ }^{27}$ For industries not likely to experience contracting problems, the model predicts that the share of intra-firm trade will be higher in countries with good governance. That is, for industry contract intensity below 0.2 , the red line is above the blue line. But even starting from small values of contract intensity, it is still the case that increasing the level of contract intensity of the industry raises the share of intra-firm trade less in countries with good governance than in countries with weak governance.
} 


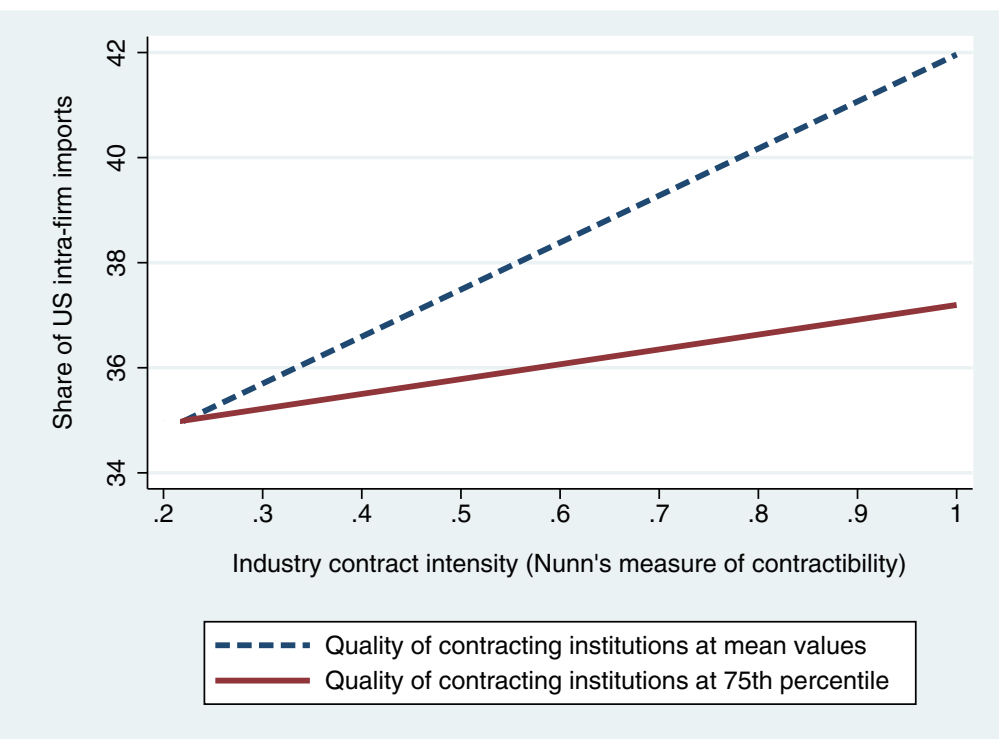

Fig. 3.15 Predicted relationship between intra-firm trade and contract intensity. Source: Authors' calculations. Note: The figure shows the predicted relationship between intra-firm and contract intensity according to the model estimated in column 2 of Appendix B "Specification for the Model of Intra-firm Trade". In the blue line the quality of contracting institutions takes the mean value of the estimated sample, while in the red line it takes the value of the 75th percentile. All the other variables of the model are measured at their mean values

\section{Policy Issues}

We have examined some of the factors that determine why some firms offshore part of their production process to external suppliers whereas others employ affiliated plants. While issues related to industry characteristics (e.g., capital intensity) or country characteristics (e.g., factor abundance) emerged as important drivers of this internalization decision, perhaps the aspect that deserves most elaboration in terms of policy implications is the issue of contracting institutions.

Therefore, we now move beyond the econometric results shown earlier and discuss in more depth how contracting institutions can shape the development of global value chains. It is argued that different legal jurisdictions across countries could segment markets in much the same ways that transport costs or tariffs do (Rodrik, 2000). For example, when an agent in a country reneges on a contract involving residents of foreign countries, local courts may be unwilling to enforce the contract, especially if such enforcement would adversely affect the local resident (Antràs, 2014). Another complication is related to enforcing a contract when the party having to pay damages does not have assets in the court's country. In general, then, ambiguous practices and uncertainty in contract enforcement can generate distrust 
between parties of different countries, thus limiting their willingness to engage in cross-border production sharing. While it is true that contractual frictions can undermine any international transaction, they can be particularly acute for transactions in global supply chains because many are related to significant relationship-specific investments. For instance, suppliers may customize their production to the specification of particular buyers. In this case, the outside option of this production might be close to 0 if the buyer decides to renege on the contract. Similarly, when the supplier does not commit to its contractual obligations, the buyer's investments are severely affected, as well as its reputation and ultimately the relationship with its own clients. Therefore, transactions in the global supply chain that typically entail customized intermediate inputs are particularly susceptible to contractual problems.

As mentioned earlier, firms might still locate slices of their value chain in countries with poor contracting institutions by establishing affiliates as a way to exercise more control. But even though this approach may facilitate the internal resolution of potential disputes, adequate contracting institutions might still be necessary. Even a multinational might need to resort to the legal institutions of a host country to solve problems with a subsidiary located there. For instance, the causes for removing a director of a subsidiary, contained in the bylaws of the company, might not apply to specific disputes, and thus the parent company might need to go to the local court of law to resolve the dispute. ${ }^{28}$ It is also possible that the subsidiary itself might need to use local suppliers to conduct part of its businesses, and these local suppliers may not respect contracts and local courts may not enforce them; again, this situation will not be attractive for the multinational. Recent evidence from China supports this last claim. Feenstra, Hong, Ma, \& Spencer (2012), for example, examine the cross-provincial variation in institutional quality in China to show that foreign firms located in China and engaged in processing trade ${ }^{29}$ tend to export more out of provinces with good judicial systems. This implies that some level of contract enforcement might be important for enabling developing countries to join international production networks even when the participation takes place through foreign subsidiaries. Therefore, it is necessary to review the state of contracting institutions in the Latin American region.

\footnotetext{
${ }^{28}$ For instance, Hong Kong technology developer CDC Corp. sued its own subsidiary, CDC Software Corp., in Atlanta, to block a sale of part of CDC Software businesses to another company. It might have taken CDC Corp. as long as 2 months to hold a meeting and exercise its right to remove the board members that voted to approve the potential operation, so CDC Corp. asked the bankruptcy court in Atlanta to issue an emergency injunction to stop the deal from progressing (The Wall Street Journal, 2012). Another example is the Dutch trading card company Upper Deck International, which filed a lawsuit against its own Upper Deck Co. subsidiary in California, claiming that by counterfeiting the Yu-Gi-Oh! card game the subsidiary cost its parent company millions of dollars in legal fees, lost sales, and damaged reputation (Anime News Network, 2011).

${ }^{29}$ In other words, these firms are clearly inserted in international supply chains.
} 
Table 3.3 Governance variables, simple average of countries in sample

\begin{tabular}{|c|c|c|c|c|c|}
\hline Variable & Range & World & LAC & EU-27 & Asia-Pacific \\
\hline $\begin{array}{l}\text { (1) No. of procedures for enforcing } \\
\text { a contract }\end{array}$ & - & 36.32 & 38.32 & 31.64 & 33.23 \\
\hline (2) Time for enforcing a contract, in days & - & 604.14 & 733.28 & 540.76 & 398.92 \\
\hline $\begin{array}{l}\text { (3) Cost for enforcing a contract, as \% } \\
\text { of claim }\end{array}$ & - & 31.64 & 31.01 & 21.38 & 30.53 \\
\hline (4) Legal formalism index ${ }^{a}$ & 1 to 6 & 3.66 & 4.41 & 3.63 & 2.97 \\
\hline $\begin{array}{l}\text { (5) Index of legal structure and security } \\
\text { of property rights }\end{array}$ & 0 to 10 & 5.89 & 4.98 & 7.27 & 6.72 \\
\hline (6) Index of property rights ${ }^{b}$ & 0 to 100 & 49.01 & 45.83 & 70.02 & 52.86 \\
\hline $\begin{array}{l}\text { (7) Index of protection of intellectual } \\
\text { property rights }\end{array}$ & 0 to 10 & 5.48 & 4.51 & 6.85 & 6.23 \\
\hline (8) Rule of law index ${ }^{b}$ & -2.5 to 2.5 & 0.05 & -0.39 & 1.12 & 0.37 \\
\hline
\end{tabular}

Notes: The table shows the simple average of the countries in the sample. The variables are: (1) the number of procedures for enforcing a contract; (2) the time (in days) for enforcing a contract; (3) the cost (as a percentage of the claim) of enforcing a contract from the Doing Business dataset, data for year 2012; (4) an index of legal formalism measuring the number of formal legal procedures necessary to resolve a simple case of collecting on an unpaid check, from Djankov, La Porta, Lopez-de-Silanes, and Shleifer (2003); (5) an index of legal structure and security of property rights, from the Fraser Institute, data for year 2012; (6) an index of property rights from the Heritage Foundation, data for year 2012; (7) an index of protection of intellectual property rights, from the Property Rights Alliance, data for year 2012; (8) an index of rule of law, from Kaufmann, Kraay, \& Mastruzzi, 2006

${ }^{a}$ Higher value corresponds to worse governance outcome

${ }^{b}$ Higher value corresponds to better governance outcome

Table 3.3 presents a battery of indicators that proxy the quality of contracting institutions for countries in Latin America as well as in other regions. The table shows the following variables: (1) the number of procedures for enforcing a contract, (2) the time (in days) for enforcing a contract, (3) the cost (as a percentage of the claim) of enforcing a contract, (4) an index of legal formalism measuring the number of formal legal procedures necessary to resolve a simple case of collecting on an unpaid check, (5) an index of legal structure and security of property rights, (6) an index of property rights protection, (7) an index of intellectual property rights protection, and (8) an index of the rule of law..$^{30,31}$

\footnotetext{
${ }^{30}$ Measures (1) to (3) come from the Doing Business dataset, measure (4) originates from the work by Djankov et al. (2003), and measures (5) to (8) come from the Fraser Institute, the Heritage Foundation, the Property Rights Alliance, and Kaufmann et al. (2006), respectively.

${ }^{31}$ Measures (1) to (4) correspond to the costs of enforcing straightforward contracts; measures (5) to (7) address the concept of property rights, and measure (8) deals with the broader concept of the rule of law. Even though there might be differences between the role of contracting institutions and the role of property rights institutions, there are also many commonalities, since both sets of institutions relate to the protection of individuals from opportunistic behavior (Acemoglu \& Johnson, 2005). As such, we include in the table the property rights measures as additional indicators that capture the general level of respect for existing agreements among citizens.
} 
The table clearly indicates that Latin America has a generally subpar record in terms of the quality of contracting institutions, compared with other regions. For instance, while the average time for enforcing a contract in the Asia-Pacific countries is 398 days, the corresponding figure for Latin America is 733 days. Similarly, while the average cost (as a percentage of the claim) for enforcing a contract in Europe is $21 \%$, the cost in Latin America is $31 \%$. Similar poorer performances are seen along the property rights index and the rule of law measure. Latin America is outperformed even by the world average in all the variables of the table except for the cost of enforcing a contract. The consistency of these comparisons suggests that the region must improve its institutions charged with regulating and enforcing contractual agreements. An example closer to the ground is presented in Box 3, which illustrates a case in which the issue of contractual uncertainty specifically undermined access to international supply chains.

\section{Box 3: Uncertain Contract Environments and Participation in GVCs}

How can uncertain contract environments limit the chances of many firms from participating in global value chains? A case involving a group of Brazilian firms that started as suppliers and subcontractors of Embraer, the Brazilian aircraft producer, might help to answer this question.

Following its privatization in 1994, Embraer went through a process of vertical disintegration in which the firm focused on its core activity as a system integrator while outsourcing most peripheral components. This vertical disintegration promoted the birth of new Brazilian firms that were founded mostly by former Embraer employees. These firms were typically small- and mediumsized and participated almost exclusively as Embraer suppliers. Over time, however, they adopted strategies for joining the global supply chains of other aircraft producers and subsystem manufacturers. In the process, they received support from Apex, the Brazilian Trade and Investment Promotion Agency.

Apex's strategy was to create an export consortium among these firms to enable them to overcome two major constraints. First, many of the activities necessary for accessing international markets, such as participating in international fairs, developing marketing strategies, or solving logistics weaknesses, entail many fixed costs; firms participating in the consortium could share these costs. Second, in the commercial aircraft industry, aircraft producers tend to give preference to suppliers that can provide complete products rather than small parts or partial components; consortium participants could supply a more complex product through the complementary work of each party.

The consortium, called High Technology Aeronautics (HTA), consisted of eight small and medium enterprises. Each member paid an entrance fee and a monthly charge to support the consortium's activities, and each had one vote in the general meetings. According to its statutes, HTA would sign a contract directly with a client and subcontract the production to individual members. 


\section{Box 3: (continued)}

While the idea of the export consortium looked good on paper, it did not work well in practice, particularly in the area of contractual practices. According to Apex, Brazil does not have adequate legal provisions for regulating consortia. Therefore, the agency decided that all of what they termed "exporting consortia" receiving its support—including HTA—should adopt the legal structure of a nonprofit association. This decision became the Achilles' heel of the initiative. In addition to the obvious limitation that this type of association cannot have profit as its main goal, casting the HTA as a non-profit association had other shortcomings. For example, the assets of the association could consist only of the fees paid by its members and other funds and donations, and the associates were not directly liable for the association's obligations. In an attempt to deal with some of these weaknesses, the HTA decided to constitute itself as a private limited liability company, $99 \%$ owned by the nonprofit association. However, this partial remedy was not sufficient to overcome the original limitations.

The flaws of the HTA's design became evident after it proved incapable of entering into contracts with global firms in the industry. For instance, after Pratt \& Whitney, a global producer of turbines, contacted HTA, Pratt \& Whitney decided to write a contract directly with one of the members of the consortium rather than with HTA. The reason was that Pratt \& Whitney did not feel sufficiently secure in entering into a contract with a consortium formed as a nonprofit association that lacked significant assets. In addition, Pratt \& Whitney did not know at the outset the identity of the company that would effectively be responsible for the production of the components.

While this example shows the difficulties of legally characterizing associative forms such as a consortium, it also illustrates the more general issue that global firms might be reluctant to engage in partnerships with local suppliers if there is uncertainty and ambiguity in contracting practices.

Source: based on material from Cafaggi et al. (2012) and Joppert Swensson (2012).

\section{Service Offshoring: Grasping the Intangibles}

Chapter 2 described the increasing trend of international fragmentation of production not only in goods but also in services. Global production networks originally involved the offshoring of manufactured intermediate inputs, but firms are also increasingly locating business functions abroad that were traditionally performed in-house. These services include computer software development, accounting, auditing and bookkeeping, and database and other information services, which for the most part can be delivered electronically; in other words, they are intangibles. We also showed in Chap. 2 that the performance of Latin America in exporting some of 


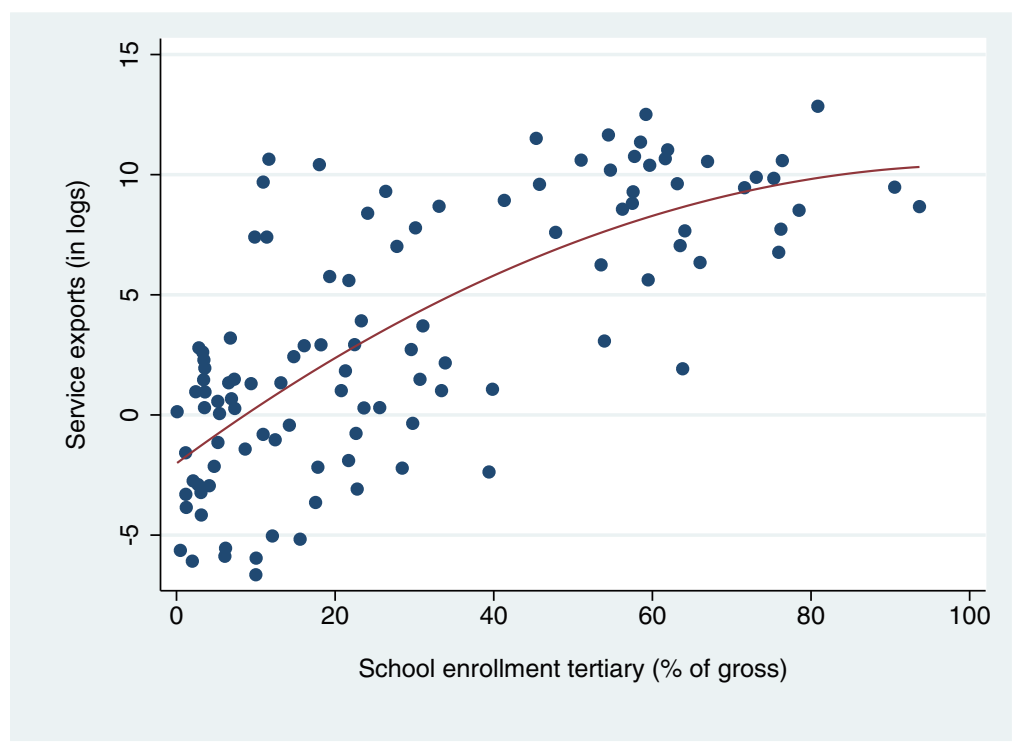

Fig. 3.16 Service exports and human capital. Source: Authors' calculations

these services is on average below the norm. In this section we discuss some of the main factors that can improve the prospects of exporting these types of services.

The literature examining trade in services is quite extensive (for a general treatment of the subject, see Mattoo, Stern, \& Zanini, 2008), and the list of potential determinants is as varied as the type of services being offshored. For instance, countries endowed with beautiful landscapes are likely to export tourism services, while countries with a long history of financial development are likely to export financial services. Similar to trade in goods, a country's comparative advantage, determined in part by relative endowments, can go a long way in shaping the patterns of specializing in exports of specific services (Deardorff, 1985). Nevertheless, a growing body of empirical studies indicates that at least two factors seem to be important for exporting a wide range of services related to GVCs: an adequate pool of human capital and a satisfactory telecommunication infrastructure that facilitates the electronic delivery of the services (Amin \& Mattoo, 2008; Freund \& Weinhold, 2002; Lennon, 2006; Lennon, Mirza, \& Nicoletti, 2009; Mirza \& Nicoletti, 2004; Shingal, 2010).

Figures 3.16 and 3.17 present the correlations between the exports of some GVC-related services and measures of human capital and telecommunication infrastructure, respectively. In particular, we add the exports flows of two service categories: "computer and information services" and "miscellaneous business, professional, and technical services." 32 The latter category includes services related

${ }^{32}$ The source is the Service Trade Database of the United Nations. 


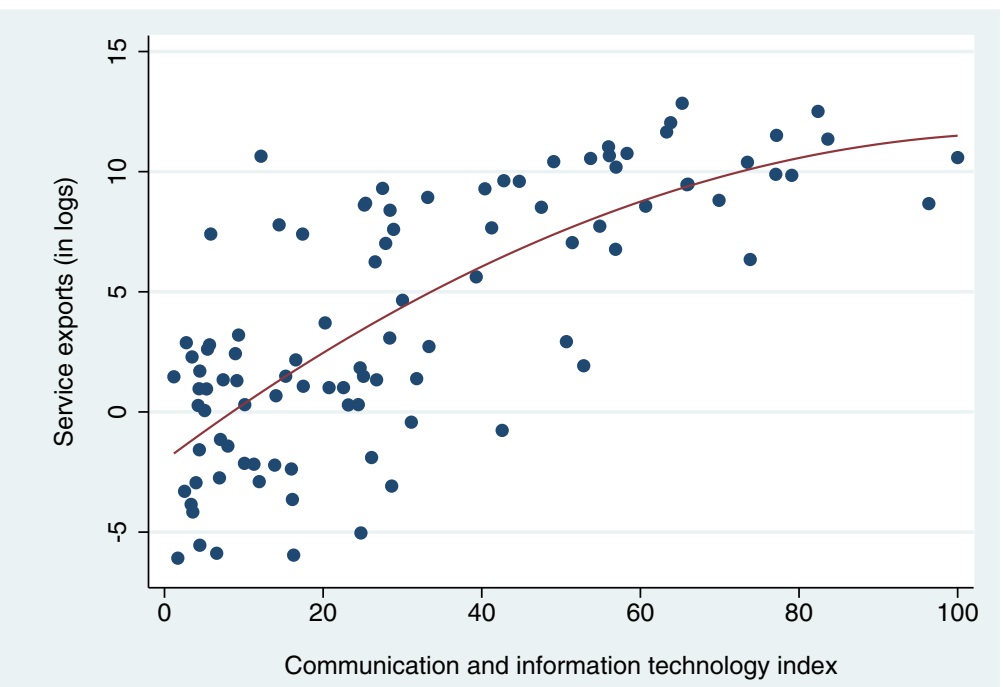

Fig. 3.17 Service exports and ICT. Source: Authors' calculations

to business and knowledge process outsourcing. The measures of human capital and telecommunication infrastructure are the country's tertiary education school enrollment and the index of information and communication technology presented earlier in this chapter. This preliminary evidence shows that indeed there is a positive correlation between the exports of these GVC-related services and measures of human capital and telecommunication infrastructure.

However, there is considerable variation in the data, indicating that the relationships between the exports of these services and the explanatory variables are not perfect. The reason is that other factors also affect the prospects of exporting these services. In what follows we perform an econometric analysis that controls for the impact of different determinants. The standard model in this literature is based on a gravity equation that relates bilateral exports of services between two countries to the income per capita and the size of those countries, the quality of the telecommunication infrastructure in both countries, a proxy for the level of human capital in the exporting country, and a vector of bilateral variables that includes the distance between the countries and whether the countries share a common border, language, and colonial ties (for a summary on gravity models for trade in services, see Grover, Gupta, Mattoo, \& Sáez, 2012). We follow this specification in a model that also controls for time-invariant country and sector characteristics and also for shocks that may affect all the countries at the same time (for more details, see Appendix B "Specification for the Model of Service Offshoring").

The results, shown in detail in Appendix B "Specification for the Model of Service Offshoring", confirm the existence of the positive relationship seen in Fig. 3.16 between the exports of GVC-related services and human capital. 
Interestingly, when we examine the role of different proxies of human capital, including the secondary (and tertiary) school enrollment ratio and the total number of pupils at the secondary level, we obtain the most robust and significant relationship with the last variable. This suggests that while the quality of education may be an important factor, this by itself might not be enough if there is not a sufficiently large pool of individuals with the right skills to supply the market. This finding echoes recent analyses of, for instance, Costa Rica, which argue that even though the country has a good educational system, it needs to increase the quantity of human capital to continue thriving in the information and knowledge-intensive sectors (OECD, 2012).

The second important result from the estimation is that having an adequate ICT infrastructure is also associated with superior performance in service exports. The estimation shows that good ICT is important for both the exporting and the importing countries: such infrastructure facilitates not only sending but also receiving the information at the other end. ${ }^{33}$ Another result worth highlighting is the role of languages. The findings imply that countries sharing the same language tend to trade these services $30 \%$ more than countries that do not share the same language.

A final notable result of the estimation is the role of distances. There is a general notion that the growth of Internet penetration in the last two decades has allowed many companies to locate business functions previously performed at home in other countries. The results from our ICT infrastructure measure support this notion. But if the Internet is all that it takes to offshore business services abroad, we should not see any role played by distance when examining the determinants of this type of trade. However, the econometric results indicate that distance generates a negative and significant impact. Other authors have found the same: physical distance reduces the exports of commercial services (Lennon, 2006) as well as finance, IT services, and miscellaneous services (Head, Mayer, \& Ries, 2009). The study by Head et al. (2009) is interesting because its year-by-year estimations are consistent with the general notion of the growing importance of the Internet and the diminishing effect of distance from 1996 to 2006. The authors also find that the distance effect does not disappear entirely, but settles after the initial decline. In our own exercise, we also run year-by-year specifications similar to those in Head et al. (2009) and find some support for the decreasing role of distance (see Fig. 3.18).

The fact that distance matters implies that even though many of these services are provided through the Internet, they may need to be tailored to the specific buyer's requirements and monitored for quality. Some of these activities might require face-to-face interactions at some point, and in general they are likely to be more effective if the buyer and the provider are located not too far apart. This has been confirmed by other authors who have analyzed the specific role of Internet penetration in service trade (Freund \& Weinhold, 2002).

\footnotetext{
${ }^{33}$ Similar results are obtained in Mirza and Nicoletti (2004).
} 


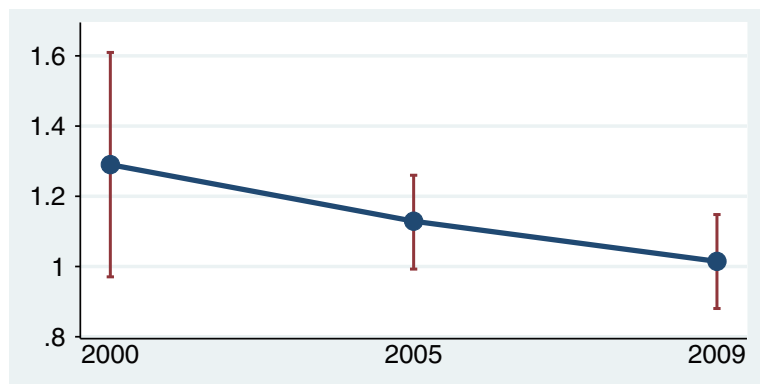

Fig. 3.18 Estimated impact of distance on service exports. Source: Authors' calculations. Note: The figure shows the elasticities of bilateral exports of services with respect to distance, estimated with the negative binomial model for 3 different years (see Appendix B "Specification for the Model of Service Offshoring"). The vertical lines denote the $95 \%$ confidence intervals

\section{Policy Issues}

The export of certain business or knowledge-intensive services can demand specific skills that might change quickly over time. The econometric results in this section indicate that with respect to human capital, it is not only the quality but also the quantity of individuals that is important. Sustaining an adequate pool of skills can be challenging. Sometimes the difficulty is education curriculums that do not prepare students with the skills needed for employment in a changing labor market. In many cases, countries have succeeded in overcoming this problem by creating alliances between the private sector, academia, and the public sector. In the Philippines, for example, the Technical Education and Skills Development Agency works in collaboration with the private sector to sustain an adequate pool of professionals in business process outsourcing (BPO) services. Some of the areas in which the agency is involved include surveys to gather information about the required skills, curriculum design, accreditation systems for training institutions, and funding of intensive training programs for college graduates who are not quite ready for the workforce.

The lack of an adequate pool of skills can also be addressed at least temporarily by employing foreign nationals. However, this may be difficult in many countries where stringent restrictions are imposed on the entry of professionals from other countries. Figure 3.19, for example, shows a restrictiveness index for the temporal movement of professionals in accounting and auditing services. Even though, on average, Latin America compares favorably with other regions, many countries impose restrictions that are quite high. In general, greater liberalization of professional and technical services can be an effective way to supply capabilities required to serve specific segments of the offshore services.

The econometric results also show that a common language plays an important role in providing GVC-related services. This represents an opportunity but also a 


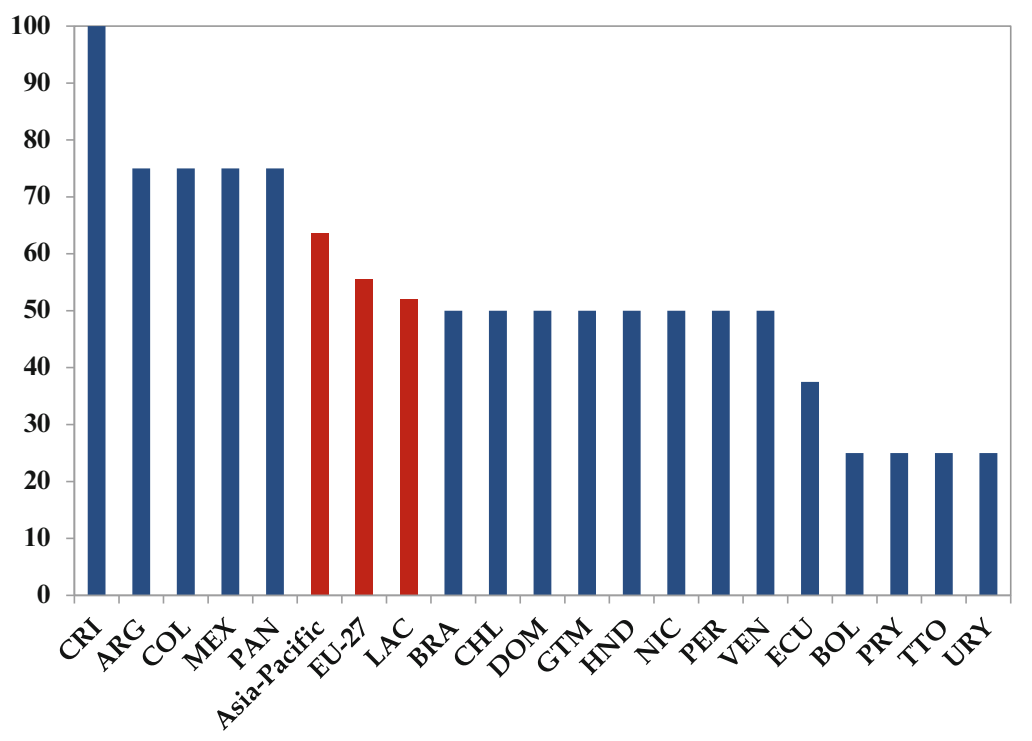

Fig. 3.19 Restrictiveness index for trade in accounting and auditing services, 2008. Source: Authors' calculations based on the Services Trade Restrictions Database (WB). Note: The figure shows the service trade restriction index for trade in accounting and auditing services. The index goes from 0 to 100, with higher values representing higher restrictions

challenge for many countries in Latin America, particularly for services aimed at the North American market. For instance, there is a growing Spanish-speaking market in the US, with a traditional demand for "call center" services, but which could eventually require IT and specialized business services as well. This is clearly an opportunity. However, the largest market in the US will continue to be the Englishspeaking segment, and the results from the model imply the importance of developing proficiency in English if this segment is to be targeted.

The fact that proximity plays a significant role in the provision of many services gives Latin America an edge relative to distant countries in Asia or Europe in targeting the US market. The region's advantages are particularly significant for exporting business functions that might require similar time zones or involve specific customization to the client's needs, and for which proximity is an important factor. Box 4 presents two examples in Latin America of firms specialized in exporting customized IT services to the US; in both cases, proximity to clients clearly contributed to their success.

Finally, it has been noted that the countries in Latin America should coordinate efforts to attract more offshore services to the region to encourage potential clients to identify the region as a favorable hub for offshoring (Gereffi, Castillo, \& Fernandez-Stark, 2009). Greater collaboration across the region might take the form of cross-fertilization of experiences and ideas, as well as cooperation in disseminating information regarding the region's capacities, attributes, and qualities. 


\section{Box 4: Exporting Customized IT Services}

It has been well documented that when a product specification cannot be easily codified (for instance, because the product requires customized features), the buyer and supplier engage in frequent face-to-face interactions and high levels of explicit coordination to ensure that the relevant information is properly transmitted (Gereffi et al., 2005). This is the case not only in manufacturing but also in services. Following are two examples of firms in Latin America that had an advantage in exporting customized IT services to the US because proximity facilitated the transmission of such knowledge between the clients and the providers.

Avionix. Embedded software integrates systems from third-party electronics components. In the aeronautics industry this software can be very sophisticated and tends to be customized to a product's particular specifications. For example, the new Boeing 787 Dreamliner requires about 6.5 million lines of tailor-made software code for the plane's avionic and onboard support systems.

In 1998, Avionix opened its first engineering facility in Melbourne, Florida, to develop avionic embedded software. In 2004, the firm opened a second engineering facility in San Jose, Costa Rica. Over the next 3 years, all the engineering operations were moved to the Costa Rica facility. Avionix has completed projects for virtually every aircraft subsystem, including navigation, weather/traffic/terrain surveillance, communication, flight control, cockpit displays, etc. The main clients of Avionix are in the US, for which the firm develops software customized to the client's specifications in a process that requires a continuous flow of communication between Avionix and the client.

According to the company, Costa Rica offers important advantages over other major IT offshoring destinations, such as India. The advantages are most significant for the development of customized software for clients located in the US. For instance, a similar time zone with the US is very important for arranging weekly teleconference status meetings, which are necessary to meet coordination needs.

Proximity is critical for other reasons as well. For example, unlike PC or Web development projects, hardware containing the embedded project is generally developed in parallel with the software. This requires a great deal of communication with the client. Also, multiple revisions of the hardware may need to be shipped offshore to the supplier to support the development of the software, and proximity helps to keep these shipping costs low relative to the more distant competitors, such as India.

Softek. There is a growing trend for outsourcing IT services for functions ranging from software development to monitoring and managing a company's IT systems, including website creation, database analysis, data storage, and testing. 


\section{Box 4: (continued)}

The Mexican firm Softek provides a wide range of IT services, including application-related services, software testing, server and datacom services, and procurement services. While the company's initial clients were located in Latin America, Softek ventured into the US market after realizing the critical importance of proximity to customers in need of swift solutions to business problems.

According to the company, geographic proximity is particularly important for scoping projects and assessing clients' needs. The company targets a market niche of tailor-made software applications and IT services that require direct, agile, and constant communications with the client. The firm's location in Mexico qualifies it for NAFTA's short-term visas, which facilitate quick trips to the US. Such flexibility and agility to respond to client needs is not necessarily offered by large software producers in distant countries, such as India or China. By differentiating its products, targeting the tailor-made software market, and using proximity to its advantage, Softek avoids direct price competition with its counterparts in Asia.

These examples illustrate how the region can successfully compete with lower-cost IT offshoring destinations in Asia by exploiting segments of the offshore services in which there are clear comparative advantages, such as in the tailor-made and customized solutions. These are products in which the exchange of tacit information between the buyer and the supplier requires frequent face-to-face interactions as well as a great deal of coordination. Similar time zones and geographic proximity provide a natural competitive edge for delivering these services.

Sources: the example of Avionix is based on material from Monge-Gonzalez and Zolezzi (2012). The case of Softek is based on material from BrownGrossman and Domínguez-Villalobos (2012).

Open Access This chapter is distributed under the terms of the Creative Commons Attribution Noncommercial License which permits any noncommercial use, distribution, and reproduction in any medium, provided the original author(s) and source are credited. 